NBER WORKING PAPER SERIES

\title{
GROUP-BASED VOTING IN MULTICANDIDATE ELECTIONS
}

\author{
Laurent Bouton \\ Benjamin G. Ogden \\ Working Paper 23898 \\ http://www.nber.org/papers/w23898 \\ NATIONAL BUREAU OF ECONOMIC RESEARCH \\ 1050 Massachusetts Avenue \\ Cambridge, MA 02138 \\ October 2017, Revised June 2018
}

A previous version of this paper was circulated under the title "Ethical Voting in Multicandidate Elections". We benefited from the comments and suggestions by Christian Basteck, Micael Castanheira, Andrew Eggers, Vincent Pons, Randy Stevenson, and Clemence Tricaud, by seminar participants at the London School of Economics, Université Lille 1, University of Chicago, and the Political Economy Webinar, and by conference participants at the American Political Science Association, the D-TEA Workshop 2017, the Econometric Society Winter Meetings, the European Political Science Association, and the Public Choice Society. This project has received funding from the European Research Council (ERC) under the European Union's Horizon 2020 research and innovation programme (grant agreement No 637662). Special thanks to Yewon Kwan for her work on the figures. The views expressed herein are those of the authors and do not necessarily reflect the views of the National Bureau of Economic Research.

NBER working papers are circulated for discussion and comment purposes. They have not been peer-reviewed or been subject to the review by the NBER Board of Directors that accompanies official NBER publications.

(C) 2017 by Laurent Bouton and Benjamin G. Ogden. All rights reserved. Short sections of text, not to exceed two paragraphs, may be quoted without explicit permission provided that full credit, including $(\subset$ notice, is given to the source. 
Group-based Voting in Multicandidate Elections

Laurent Bouton and Benjamin G. Ogden

NBER Working Paper No. 23898

October 2017, Revised June 2018

JEL No. C72,D72

\begin{abstract}
$\underline{\text { ABSTRACT }}$
We study the properties of the group-based model of voting in elections with more than two candidates. We consider two of the most widely used electoral rules around the world: plurality and majority runoff. We fully characterize the set of equilibria under both rules and identify the features of an election that favor different types of voting behavior: either sincere voting or coordination behind a limited number of candidates. Comparing plurality and majority runoff, we find that the incentives to vote sincerely are stronger under the latter, in line with empirical evidence. Our analysis uncovers several strengths of the group-based model of voting: it is tractable, the predictions are empirically sound, and, due to equilibrium uniqueness for a broad set of parameter values, quite crisp. Some results appear sensitive to the composition of groups in the electorate, highlighting the structure of group identity as a key determinant of voting behavior.
\end{abstract}

Laurent Bouton

Georgetown University

Department of Economics

37 th \& O Streets, NW

Washington,DC 20057

and CEPR

and also NBER

boutonllj@gmail.com

Benjamin G. Ogden

Texas A\&M University

300D N Parker Ave

Bryan, TX 77803

bgogden@tamu.edu 


\section{Introduction}

Voters ought to be a central piece within formal models of politics. Yet, more often than not, they take the backstage: they are assumed to support the alternative they like most without pondering the consequences of their actions. They are expressive. While not supported by the facts ${ }^{1}$, this approach to voters' behavior is, in the minds of many, not necessarily dominated by the fully rational workhorse model of strategic voting, i.e. the pivotal voter model (see, e.g., Riker and Ordeshook 1968, Ledyard 1981, Palfrey and Rosenthal 1983,1985, Myerson and Weber 1993, Cox 1997, Myerson 1998, 2002, Myatt 2007). Indeed, this model is also afflicted by serious weaknesses: the most salient being the counterfactually low turnout levels it predicts-highlighting the so-called paradox of voting. ${ }^{2}$ These weaknesses have made this approach the target of frequent and sometimes scathing criticisms (see, e.g., Fiorina 1989, Grofman 1993, Green and Shapiro 1994). Political science as a field is impeded by this lack of consensus about how formally model voters' behavior.

The challenge of finding improved formal models of voter behavior has not been left unanswered. The so-called group-based model of voting is one of those alternatives (Harsanyi 1977, 1992, Ulhaner 1989, Morton 1987, 1991, Shachar and Nalebuff 1999, Coate and Conlin 2004, Feddersen and Sandroni 2006a, 2006b, Herrera and Martinelli 2006, Ali and Lin 2013, and Levine and Mattozzi 2016). In that model, for different reasons spanning ethical motives, leaders' influence, and mobilization efforts, voting decisions

\footnotetext{
${ }^{1}$ There are various pieces of evidence that go against the assumption of purely expressive voting. First, the literature comparing each voter's actual vote to her preferences finds a fraction of voters casting misaligned votes (i.e., voting for another candidate than their most-preferred) ranging from $3 \%$ to $17 \%$ (e.g., Alvarez and Nagler 2000, Blais, Nadeau, Gidengil, and Nevitte 2001 and papers cited therein). Second, recent studies (Kawai and Watanabe 2013, Spenkuch 2017) find that a larger fraction of voters are strategic (estimates range from $40 \%$ to $85 \%$ ), but they do not necessarily cast a misaligned vote. Third, the experimental literature finds evidence of strategic voting both in two-candidate elections (for both the costly voting side, e.g., Palfrey and Levine 2007; and the Condorcet jury theorem side, e.g., Guarnaschelli et al. 2000, Battaglini et al. 2008, 2010, Goeree and Yariv 2011, Bhattacharya et al. 2014, Bouton et al. 2017a) and in multicandidate elections (e.g., Forsythe et al. 1993 and 1996, Fisher and Myatt 2001, Morton and Rietz 2008, Bouton et al. 2016, 2017b). Fourth, studies also find evidence of strategic voting through its implications on the number of "serious" candidates under different electoral systems (e.g., Fujiwara 2011). Finally, the empirical literature that studies voter turnout uncovers voting behavior that is not coherent with the sincere voting assumption (e.g., Coate and Conlin 2004, and Coate, Conlin and Moro 2008).

${ }^{2}$ Feddersen (2004) defines this paradox eloquently: "If each person only votes for the purpose of influencing the election outcome, then even a small cost to vote (...) should dissuade anyone from voting. Yet, it seems that many people will put up with long lines, daunting registration requirements and even the threat of physical violence or arrest in order to vote" (p. 99).
} 
end up being made as if at the group level. That model predicts high turnout level (no paradox of voting), and produces comparative statics that appear empirically sound (see the discussion in Feddersen and Sandroni 2006a). Moreover, direct tests of this model (both on observational and experimental data) are quite encouraging (Coate and Conlin 2004, Feddersen, Gailmard, and Sandroni 2009, Morton and Tyran 2012).

While promising, all of these results concern elections with two alternatives. But, most real-life elections involve more than two candidates or parties (Jones 2001). In those elections, the strategic behavior of voters is more involved: on top of deciding whether to vote, they have to determine for whom to vote. To have a chance of being endorsed more widely, the group-based model of voting must also perform well when applied to the study of multicandidate elections.

In this paper, we develop a group-based model of voting in multicandidate elections. Our focus is on voters' decisions for whom to vote. We study two of the most-widely used electoral rules around the world: the plurality rule $^{3}$ and the majority runoff rule. ${ }^{4}$ Our initial results confirm the promises of the group-based model. The predictions are empirically sound and, due to equilibrium uniqueness for a broad set of parameter values, quite crisp. Moreover, the model is tractable. Some results appear sensitive to the number and types of groups in the electorate, further emphasizing that the structure of group identity is a key determinant of voting behavior. This calls for a better understanding of the formation of voting groups and the coordination of their members; an understudied topic (see Herrera and Martinelli 2006 for an exception).

The main novelty of this paper is that we consider a setup with more than two can-

\footnotetext{
${ }^{3}$ In plurality elections (a.k.a. first-past-the-post), voters can vote for one of the candidates in the running, and the candidate with the largest number of votes wins. This system is used in many countries, e.g. the U.K. and the U.S., to elect members of the lower house of their legislature.

${ }^{4}$ In a majority runoff election, there are up to two rounds of voting. In each round, voters can vote for one of the participating candidates. In the first round, all candidates participate, and a candidate wins outright if she obtains an absolute majority of the votes. If no candidate wins in the first round, then a second round is held between the top-two vote getters. The winner of that round wins the election. This is the most-widely used system to elect presidents around the world (Bormann and Golder 2013).
} 
didates. ${ }^{5}$ In our baseline case, we consider the so-called divided majority setting. ${ }^{6}$ There are three candidates (A, B, and $\mathrm{C}$ ) and three types of voters (a, b, and c). A majority of voters prefer both A and B (the majority candidates) over C (the minority candidate). The majority is divided: a-voters prefer candidate A over candidate B, but b-voters prefer candidate B over candidate $\mathrm{A}$. The support for candidate $\mathrm{C}$ is sufficiently large so that she is a serious threat. This simple case is useful to discuss key features of the strategic behavior of voters and highlights important characteristics of the set of equilibria. We then extend the model in several directions in order to refine our results and/or show their robustness. In particular, we allow for (i) a more sophisticated structure of preferences (which nests the ubiquitous case of a policy space with single-peaked preferences), (ii) more voting groups, and (iii) the presence of expressive voters, who always vote for their most-preferred candidate.

Our analysis focuses first on (pure strategy) equilibria under plurality rule. In our baseline model, there are two types of equilibria: (i) the sincere voting equilibrium (in which voters vote for their most-preferred candidate), and (ii) Duverger's Law equilibria (in which all majority voters vote for the same majority candidate, either A or B). ${ }^{7}$ We prove that an equilibrium always exists, and that it is unique for a broad range of parameter values. Moreover, equilibrium multiplicity only happens when the two Duverger's law equilibria exist. In other words, the sincere voting equilibrium never coexists with Duverger's law equilibria. Thus, our model uniquely predicts the number of candidates receiving a positive share of the votes. This later result proves only partially robust to the inclusion of some additional groups of voters: it remains true when the number of groups

\footnotetext{
${ }^{5}$ In an independently developed paper, Li and Pique (2016) explore ethical motives for strategic voting in multicandidate elections. Their approach is complementary to ours: they work under the assumption that it is costly for voters to cast a misaligned vote but that ethical motives may nonetheless lead them to do so. One crucial difference between their results and ours is about the effect of the strength of a voter's least preferred candidate on her propensity to cast a misaligned vote. Their model predicts that this effect is non-monotonic whereas ours predicts it is monotonic. As we discuss below, empirical evidence seems to support our finding. Another important difference is that they focus on plurality elections, while we consider both plurality and runoff elections.

${ }^{6}$ The divided majority setting is tractable but still captures the fundamental coordination problems that voters face in multicandidate elections. As a consequence, this setting is widespread in the literature on strategic voting in multicandidate elections (e.g., Palfrey 1989, Myerson and Weber 1993, Cox 1997, Fey 1997, Piketty 2000, Myerson 2002, Dewan and Myatt 2007, Myatt 2007, Bouton and Castanheira 2012, and Bouton 2013).

${ }^{7}$ Adding groups of voters with different preference orderings to the model allows for a third type of equilibria: partial Duverger's law equilibria, in which some, but not all, supporters of a candidate abandon their most-preferred candidate in order to rally behind a more serious contender. We study those equilibria in Section 5.2.
} 
increases but not as the number of preference orderings present in the electorate becomes sufficiently large. In that sense, the predictions of the group-based model of voting are sensitive to the structure of group identity in the electorate. This sensitivity generates interesting predictions about Duverger's law: it is more likely to hold when groups with similar interests are fragmented. This may help explain the mixed empirical evidence on the topic (e.g., Grofman, Blais and Bowler (2009).

Our equilibrium characterization allows us to identify the features of an election that favor sincere voting-that is, when Duverger's law should fail. ${ }^{8}$ Quite intuitively, the incentives to vote sincerely are stronger when (i) the utility differential between the two majority candidates is large, (ii) the utility differential between the less preferred majority candidate and the minority candidate is small, (iii) the minority group is small, and (iv) the majority is evenly divided. The importance of cardinal utilities for equilibrium behavior in large elections is a distinguishing feature of the group-based voting model. These results find support in the empirical literature (e.g., Blais and Nadeau 1996, and Bouton, Castanheira, and Llorente-Saguer 2016).

We also characterize the set of equilibria under the majority runoff rule. In the first round, voters incentives are qualitatively similar as under plurality, but quantitatively different. Comparing the two systems, we find that the incentives to vote sincerely are stronger under majority runoff. ${ }^{9}$ In particular, if the sincere voting equilibrium exists under plurality, it also exists (and is unique) under majority runoff. Conversely, if a Duverger's law equilibrium exists under majority runoff, then it also exists under plurality. This result is consistent with the empirical findings that Duverger's law forces are sometimes (see Fujiwara 2011, on Brazilian data), but not always (see Bordignon et al. 2016, on Italian data) stronger under plurality than under runoff. Moreover, we identify the characteristics of the election for which the difference in the strengths of the Duverger's law forces should be noticeable: that is, when Duverger's law and hypothesis should both hold. ${ }^{10}$ This presents an opportunity to revisit the data having in mind the characteris-

\footnotetext{
${ }^{8}$ Duverger's law says that "the simple-majority single-ballot system [the plurality electoral system] favors the two-party systems" (Duverger 1963, p. 217).

${ }^{9}$ We also analyze French-style runoff elections, in which candidates obtaining a number of first-round votes larger than a threshold number of votes are allowed to participate in the second round. Perhaps surprisingly, in such runoff elections, the incentives to vote sincerely are stronger than under plurality but weaker than under majority runoff.

${ }^{10}$ Duverger's hypothesis says that "the simple-majority system with second ballot [the runoff electoral system] favors multi-partyism" (Duverger 1963, p.239).
} 
tics of the electoral environment for which the incentives to vote sincerely are different in plurality and runoff elections. ${ }^{11}$

There are several dimensions along which the group-based voting model fares well. First, it produces relatively crisp predictions: the equilibrium is unique for a broad set of parameter values. Moreover, even when there are multiple equilibria, there remains no ambiguity about the number of "serious" candidates, i.e. those receiving a positive vote share, as long as the number of voting groups with different preference orderings is limited. In the remaining cases, it is not possible that supporters of more than one candidate have misaligned votes. This greatly limits the scope of non-sincere behavior when Duverger's law does not hold fully. By contrast, even when the number of preference orderings is limited, the pivotal voter model always produces multiple Duverger's law equilibria, ${ }^{12}$ as well as a non-Duverger's law equilibrium, in which more than two candidates are serious. ${ }^{13}$ In a companion paper (Bouton and Ogden 2018), we exploit these properties of the groupbased model to analyze the behavior of candidates in multicandidate elections when voters are strategic. We revisit classic models of candidates behavior (entry and positioning along the real line) and find that the presence of strategic voters dramatically affects the behavior of candidates.

Second, the group-based voting model produces sound predictions. There are multiple Duverger's law equilibria only in elections in which the coordination of majority voters is absolutely necessary (i.e. the minority candidate is a serious threat), and there is no majority candidate clearly stronger than the other (i.e. the majority is evenly divided). By contrast, the pivotal voter model predicts that essentially any candidate can be a

\footnotetext{
${ }^{11}$ Such an analysis should take into account the findings of models with expressive voters and strategic candidates that also identify situations in which Duverger's law and hypothesis both hold (e.g., Osborne and Slivinski 1996, Callander 2005).

${ }^{12}$ This is so because the pivotal voting logic gives full power to self-fulfilling prophecies: in order not to waste their votes, voters have an incentive to abandon their most-preferred candidate if they expect her not to have a serious shot at winning.

${ }^{13}$ A cursory read of Myatt (2007) may suggest that the presence of aggregate uncertainty about the distribution of preferences in the electorate is sufficient to eliminate Duverger's law equilibria and guarantee equilibrium uniqueness in the pivotal voter model. This is not the case: Myatt (2007) indeed acknowledges the existence of Duverger's law equilibria in his setup but then discards them to instead focus on the properties of non-Duverger's law equilibria. He does not study how the presence of aggregate uncertainty affect Duverger's law forces and equilibria. As shown by Bouton et al. (2017), Duverger's law forces remain strong as long as the amount of aggregate uncertainty is such that a candidate abandoned by almost all her supporters cannot be perceived as the main contender to defeat the minority candidate. Arguably, this is an unreasonable amount of aggregate uncertainty. Duverger's law equilibria should thus exist in most situations (which does not mean that they are always being played). A similar result appears in Fisher and Myatt (2017).
} 
serious contender for victory in equilibrium, even one that is ranked behind another given candidate by all voters. Additionally, non-Duverger's law equilibria (i.e., sincere voting equilibrium and the partial Duverger's law equilibria in the extended model) exist only when the minority candidate is not too much of a threat and both majority candidates are strong. Moreover, they involve straightforward voting behavior: voters either all vote for their most-preferred candidate, or some of them rally behind a stronger alternative. By contrast, in the pivotal voter model (with aggregate uncertainty), the non-Duverger's law equilibrium exists as long as each majority candidate may be perceived as having more support in the electorate than the minority candidate. ${ }^{14}$ Majority voters then vote in such a way that balances the risk of a victory of the minority candidate across states of nature. This may require that some supporters of the stronger majority candidate give their vote to the weaker majority candidate. Finally, even when the electorate is large, the intensity of voter preferences influences equilibrium behavior in the group-based model. Empirical evidence, and common sense, suggests that preference intensities play an important role in shaping voters' behavior in real-life elections (e.g., Blais and Nadeau 1996). By contrast, in the pivotal voter model, preference intensities do not shape equilibrium behavior in large elections.

\section{The Baseline Model}

In this section, we introduce the baseline model. This model is sufficient to discuss key features of the strategic behavior of voters and highlight important characteristics of the set of equilibria. In section 5, we extend the model in several directions in order to refine our results and/or show their robustness. In particular: (i) we allow for a more sophisticated structure of preferences, (ii) we include more voting groups, and (iii) we allow for the presence of expressive voters, who always vote for their most-preferred candidate.

We model an election with 3 candidates, $A, B$, and $C$, and a continuum of voters. ${ }^{15}$ The electoral rule is plurality (we consider majority runoff in section 4). There is an unique

\footnotetext{
${ }^{14}$ Without aggregate uncertainty, a non-Duverger's law equilibrium always exists but is often considered as unreasonable and unstable (Fey 1997).

${ }^{15}$ Our group-based voting model accommodates easily more than three candidates. When there are $N>3$ candidates, we can still identify situations where the sincere voting equilibrium exists (in this case, $N$ candidates receive a positive vote share when voters vote sincerely). As in the baseline model, the sincere voting equilibrium never coexist with the Duverger's law equilibria (where two candidates receive a positive vote share).
} 
round of voting in which all voters are called to cast a vote for one of the candidates in the running. The action set is denoted by $\Psi=\{A, B, C\}$. The candidate with the largest number of votes wins.

Each voter has preferences over the set of candidates. The distribution of preferences in the population follows the so-called divided majority case. There are majority voters who prefer $A$ and $B$ over $C$ and minority voters who prefer $C$ over $A$ and $B$ (and, for the sake of simplicity, are indifferent between $A$ and $B) .{ }^{16}$ The majority is divided into two groups: $a$-voters who prefer $A$ over $B$, and $b$-voters who prefer $B$ over $A$. There are thus three types of voters: $\Theta=\{a, b, c\} .{ }^{17}$

Formally, voters' preferences can be represented by the utility function $u: \Theta \times \Psi \rightarrow \mathbb{R}$. For majority voters, we assume:

$$
\begin{aligned}
& u(A, a)=W=u(B, b), \\
& u(B, a)=0=u(A, b), \text { and } \\
& u(C, a)=-Y=u(C, b),
\end{aligned}
$$

with $W, Y>0 .{ }^{18}$ For minority voters, we assume:

$$
\begin{aligned}
& u(C, c)=Z>0, \\
& u(A, c)=0=u(B, c) .
\end{aligned}
$$

This directly implies that voting for $C$ is a weakly dominant strategy for $c$-voters. ${ }^{19}$

The size of the minority (i.e., the proportion of $c$-voters in the population) is fixed at $k \in\left[\frac{1}{3}, \frac{1}{2}\right] .{ }^{20}$ Obviously, this means that the size of the majority (i.e., the proportion of $a$-voters and $b$-voters in the population) is $1-k$. The relative size of the two groups forming the majority is given by $\alpha$ : the share of $a$-voters in the population is thus $\alpha(1-k)$, and

\footnotetext{
${ }^{16}$ In section 5.1, we relax that assumption and prove that, in the real-line setting, voting for $C$ is a dominant strategy for $c$-voters as soon as the group size is larger than $1 / 3$.

${ }^{17}$ We can extend the type space to accommodate for any preference ordering over the set of candidates (see Section 5.2).

${ }^{18}$ In Section 5.3, we show that the assumption that the symmetry in the preferences of majority voters is innocuous.

${ }^{19}$ Our results are also robust to differences in cardinal preferences among voters of a same group (who have the same ordinal preferences). When there is heterogeneity in preferences among voters of a same group, what drives that group's behavior is the average preferences of the voters composing it.

${ }^{20}$ This assumption's purpose is to exclude uninteresting cases where $C$ is not a threat.
} 
the share of $b$-voters is $(1-\alpha)(1-k)$. Without loss of generality, we assume that $\alpha \leq \frac{1}{2}$.

Voters of type $\theta \in \Theta$ turn out with an (exogenously given) probability $q_{\theta}$, drawn from a Uniform distribution with support $[0,1] .{ }^{21}$ The distributions of these random variables are common knowledge but, at the time of the vote, their realizations are not. This assumption implies that there is aggregate uncertainty about the distribution of actual voters in the electorate. As in the pivotal voter model (see Myatt 2007 and Bouton et al. 2016), the presence of such aggregate uncertainty is a key feature of our model: without it, the strategic behavior of voters would be dramatically different. ${ }^{22}$ The particular way we obtain aggregate uncertainty is unimportant. For instance, we could assume that all individuals in the population turn out with a known probability, but that there is uncertainty about the proportion of voters of the different type (i.e., $k$ and/or $\alpha$ are random variables).

Following the group-based approach, we assume that voting decisions are made at the group level. ${ }^{23}$ Group members vote in order to maximize welfare of the group. ${ }^{24}$ Given the dominant strategy of $c$-voters and that members of a group have the same preferences, the game essentially simplifies to a two-player game (one player choosing group- $a$ action and one player choosing group- $b$ action). Denoting by $\lambda_{i} \in[0,1]$ the probability that a member of group $i$ votes for $A,{ }^{25}$ a Bayesian Nash Equilibrium is a tuple $\left\{\lambda_{i}^{*}\right\}_{i=a, b}$ such

\footnotetext{
${ }^{21}$ One way to think about the exogenous turnout is as the product of a (simple) costly voting model in the vein of Feddersen and Sandroni 2006a: each voter faces a (fixed) cost $\bar{c}$ if they vote. A proportion $q_{\theta}$ are ethical voters who receive a benefit from doing one's duty to the group $D>\bar{c}$, while the remainder do not, and therefore abstain (since they have infinitesimal impact upon the election). Therefore, the exogenous turnout is the same as exogenous duty with fixed cost.

${ }^{22}$ Without such uncertainty, majority voters would always coordinate behind one of the majority candidates. This candidate would then win the election with probability one.

${ }^{23}$ In Section 5.3, we allow for the presence of expressive voters, who always vote for their most-preferred candidate.

${ }^{24}$ There are different justifications for the group-based approach (see Shachar and Nalebuff 1999, Feddersen and Sandroni 2006a, 2006b, Coate and Conlin 2004, and Levine and Mattozzi 2016). In a previous version of the paper, we were following the ethical voting approach (Feddersen and Sandroni 2006a, 2006b, and Coate and Conlin 2004), by assuming that voters are "rule-utilitarian". This means they understand that there is a (group-level) rule (to be determined endogenously) that they need to follow in order for the utility of the group to be maximized, and they get a payoff if they act according to this rule (if they are "doing their part"). That payoff is assumed larger than any cost of doing ones part. As a consequence, and since the probability that one vote influences the outcome of the election is zero, voting decisions are as if made at the group level.

${ }^{25}$ Our focus on equilibria in which all members of a given group adopt the same strategy is not totally innocuous. When members of a group are allowed to adopt different strategies, e.g. $40 \%$ of $a$-voters vote for $A$ and $60 \%$ vote for $B$, then the existence of a pure strategy equilibrium is not guaranteed (but the existence of a mixed-strategy equilibrium is). However, we believe that the coordination required for asymmetric strategies within groups is quite demanding. Typically, in large groups, asymmetric strategies are implemented through mixed strategies (which is what our assumption allows for). Moreover, we can
} 
that

$$
\begin{array}{lll}
\lambda_{a}^{*} & \text { maximizes } & p_{A}\left(\lambda_{a}, \lambda_{b}^{*}\right) W-\left(1-p_{A}\left(\lambda_{a}, \lambda_{b}^{*}\right)-p_{B}\left(\lambda_{a}, \lambda_{b}^{*}\right)\right) Y, \text { and } \\
\lambda_{b}^{*} \text { maximizes } & p_{B}\left(\lambda_{a}^{*}, \lambda_{b}\right) W-\left(1-p_{A}\left(\lambda_{a}^{*}, \lambda_{b}\right)-p_{B}\left(\lambda_{a}^{*}, \lambda_{b}\right)\right) Y,
\end{array}
$$

where $p_{\psi}\left(\lambda_{a}, \lambda_{b}\right)$ is the probability that candidate $\psi$ wins when the strategy profile is $\left(\lambda_{a}, \lambda_{b}\right)$. See Lemma 4 (in Appendix A1) for detail about these probabilities.

\section{Equilibrium Analysis}

In this section, we fully characterize the set of (pure strategy) equilibria, i.e. equilibria in which voters of a given group all votes for the same candidate with probability 1 , under plurality. ${ }^{26}$ Doing so, we prove that a (pure strategy) equilibrium always exists, and that, for a broad set of parameter values, there is an unique (pure strategy) equilibrium. In the remainder of the paper, we drop the qualifier "pure strategy" and refer to "pure strategy equilibria" as "equilibria".

There are two type of equilibria in the baseline model: (i) the sincere voting equilibrium, and (ii) Duverger's Law equilibria. ${ }^{27}$

Definition 1 In the sincere voting equilibrium, majority voters vote for their most preferred candidate (strategy profile $(1,0)$ ).

Definition 2 In a Duverger's Law equilibrium, all majority voters vote for the same candidate: either candidate $A$ (strategy profile $(1,1)$ ), or candidate $B$ (strategy profile $(0,0))$.

When there are more groups of voters with different preference orderings, a third type of equilibria may exist: partial Duverger's law equilibria, in which some, but not all, supporters of a candidate abandon their most-preferred candidate in order to rally behind a more serious contender. We study those equilibria in Section 5.2.

easily capture situations in which members of a group adopt different strategies by splitting that particular group into two groups. These two groups are then free to adopt different strategies. As we show in section 5.2 , our results are robust to an increase in the number of groups.

${ }^{26}$ In Appendix A2, we show that a mixed strategy equilibrium may exist. This equilibrium involves mixing by both group- $a$ and group- $b$ voters.

${ }^{27}$ It is easy to see that $(0,1)$ cannot be an equilibrium: both group- $a$ and group- $b$ prefer to vote for their most-preferred candidate when the other majority group vote for that candidate. 


\section{$3.1 \quad$ Existence}

Our proof of existence is constructive. First, we identify the necessary and sufficient condition under which the sincere voting equilibrium exists:

Proposition 1 Under plurality, the sincere voting equilibrium exists if and only if

$$
\frac{W}{Y} \geq \frac{p_{A}(1,1)-p_{A}(1,0)-p_{B}(1,0)}{p_{A}(1,0)}
$$

The condition in Proposition 1 guarantees that, when they expect the other majority group to vote sincerely, neither group prefers voting for their second choice candidate instead of voting for their first choice. This depends both on the utility function of $a$ - and $b$-voters ( $W$ and $Y$ ), and the probabilities of winning of candidates $A$ and $B$ when voters are sincere or when they all vote for the same majority candidate $\left(p_{A}(1,0), p_{B}(1,0)\right.$, and $\left.p_{A}(1,1)\right)$. Voters are more inclined to vote for their most-preferred candidate when they care a lot about electing their preferred majority candidate (large $W$ ) and when they do not dislike the minority candidate too intensely (small $Y$ ). Sincere voting is also more appealing when candidate $A$ is a serious contender when all voters vote sincerely (large $\left.p_{A}(1,0)\right)$ and coordinating behind one majority candidate does not increase much the likelihood of defeating the minority candidate ( $\left.\operatorname{small} p_{A}(1,1)-p_{A}(1,0)-p_{B}(1,0)\right)$.

Using Lemma 4 (in Appendix A1), we can rewrite the condition in Proposition 1 as a function of only primitives of the model: $W, Y, \alpha$ and $k$. We can then prove the following Lemma:

Lemma $1 \frac{p_{A}(1,1)-p_{A}(1,0)-p_{B}(1,0)}{p_{A}(1,0)}$ is increasing in $k$ and decreasing in $\alpha$.

This Lemma shows that the sincere voting equilibrium is more likely when (i) the minority group is small (small $k$ ), then majority voters have weak incentives to coordinate behind one majority candidate to defeat the minority candidate; (ii) the majority is evenly divided ( $\alpha$ large), then both types of majority voters realize that their champion has a significant chance to win, and they do not want to relinquish that chance.

Moving to the second part of the proof of existence, we identify the necessary and sufficient condition under which a Duverger's Law equilibrium $(0,0)$ exists: 
Proposition 2 Under plurality, there exists a Duverger's Law equilibrium $(0,0)$ if and only if

$$
\frac{W}{Y} \leq \frac{p_{A}(1,1)-p_{A}(1,0)-p_{B}(1,0)}{p_{A}(1,0)}
$$

The condition in Proposition 2 guarantees that $a$-voters prefers to vote for $B$ (and thus that $b$-voters also want to do so). This is the flip side of the condition in Proposition 1. This has two consequences. First, Lemma 1 applies and informs us that the Duverger's Law equilibrium $(0,0)$ is more likely when (i) the minority group is large (large $k$ ), then majority voters have strong incentives to coordinate behind one majority candidate since it is the only way to defeat the minority candidate; (ii) the majority is unevenly divided ( $\alpha$ small), then $a$-voters realize that their champion is unlikely to win, and they thus prefer to increase the probability of defeating the minority candidate by coordinating behind candidate $b$. Second, the sincere voting equilibrium and the Duverger's Law equilibrium $(0,0)$ never coexist (except in the knife-edge case in which both conditions are satisfied with equality).

Existence of an equilibrium follows as a corollary of Propositions 1 and 2:

Corollary 1 Under plurality, an equilibrium always exists.

\subsection{Uniqueness}

From Propositions 1 and 2, we have that the sincere voting equilibrium and the Duverger's Law equilibrium $(0,0)$ never coexist under plurality. To show uniqueness, it is thus sufficient to identify conditions under which the Duverger's Law equilibrium $(1,1)$ does not exist. This is the role of the following Proposition:

Proposition 3 Under plurality, there exists a Duverger's Law equilibrium $(1,1)$ if and only if

$$
\frac{W}{Y} \leq \frac{p_{A}(1,1)-p_{A}(1,0)-p_{B}(1,0)}{p_{B}(1,0)}
$$


The condition that guarantees the existence the Duverger's Law equilibrium $(1,1)$ is more demanding than the condition for the Duverger's Law equilibrium $(0,0)$. This is so because, if all groups vote sincerely, candidate $B$ is more likely to win than candidate $A$ (i.e. $\left.p_{B}(1,0)>p_{A}(1,0)\right)$. Hence, $b$-voters have weaker incentives than $a$-voters to coordinate behind their second-preferred candidate.

As for the condition in Proposition 1, we can use Lemma 4 (in Appendix A1), to rewrite the condition in Proposition 3 as a function of the primitives of the model. We can then prove the following Lemma:

Lemma $2 \frac{p_{A}(1,1)-p_{A}(1,0)-p_{B}(1,0)}{p_{B}(1,0)}$ is increasing both in $k$ and in $\alpha$.

This Lemma shows that the Duverger's Law equilibrium $(1,1)$ is more likely to exist when (i) the minority group is large (large $k$ ), then majority voters have strong incentives to coordinate behind one majority candidate since it is the only way to defeat the minority candidate; (ii) the majority is evenly divided ( $\alpha$ large). At first sight, this second part might seem counterintuitive. Indeed, when the majority is evenly divided, it is possible that both majority candidates should have a chance to win, and voters should thus not want to abandon their champion. Yet, when the majority is evenly divided, it also might well be that both majority candidates are unlikely to win. In such a case, coordinating behind any of the majority candidate is appealing because it is the only way to defeat the minority candidate.

As a corollary of Propositions 1, 2, and 3, we have a necessary and sufficient condition for equilibrium uniqueness:

Corollary 2 Under plurality, the equilibrium is unique if and only if $\frac{W}{Y}>\frac{p_{A}(1,1)-p_{A}(1,0)-p_{B}(1,0)}{p_{B}(1,0)}$.

To better understand when the equilibrium is unique, it is useful to consider sufficient conditions on the primitives of the model. First, we can identify a sufficient condition on the utility function of majority voters:

Proposition 4 If $W \geq Y$, then $\forall k, \alpha$ there exists a unique equilibrium under plurality. Moreover, $\exists \bar{\alpha}$ (increasing in $k$ ) such that, if $\alpha>\bar{\alpha}$, the unique equilibrium is the sincere voting equilibrium. 


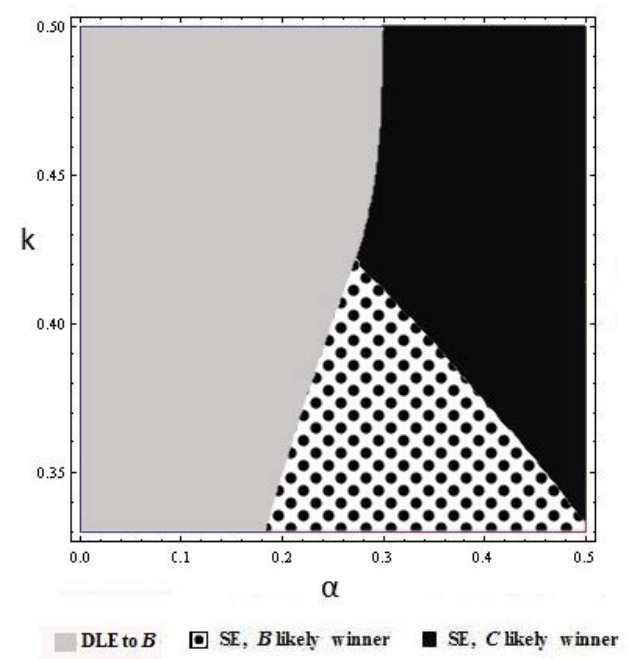

Figure 1: Equilibria with $\frac{W}{Y}=2$. The light colored area represents parameter values for which the unique equilibrium is the Duverger's Law equilibrium $(0,0)$, such that both types of voter vote for $B$. The remaining areas represent parameter values for which the unique equilibrium is sincere voting, such that each voter type votes for their first choice, with the black area representing those values for which the Condorcet loser is the likely winner.

Proposition 4 first shows that as soon as majority voters care relatively more about the choice between the two majority candidates than about preventing a victory of the minority ( $W$ larger than $Y$ ), the equilibrium is unique. This is because coordinating behind one majority candidate leads to limited gains in terms of decreasing the likelihood that $C$ wins. Therefore, $b$-voters are willing to abandon their champion only if they care relatively more about defeating the minority candidate than about choosing their preferred majority candidate.

The second part of Proposition 4 shows that, if the majority is evenly divided, the unique equilibrium is the sincere voting equilibrium. Otherwise, the unique equilibrium is the Duverger's Law equilibrium $(0,0)$. We can illustrate that result with a numerical example. Suppose that $\frac{W}{Y}=2$. Figure 1 plots the equilibrium type for all possible combinations of $\alpha$ (x-axis) and $k$ (y-axis). It also distinguishes between two types of cases when the sincere voting is the unique equilibrium: values of the parameters for which candidate $B$ is the likely winner (i.e., the candidate who wins with the highest probability), and those for which candidate $C$ is the likely winner. Figure 1 clearly illustrates that Duverger's Law fails when the majority is sufficiently evenly divided.

It is also useful to consider sufficient conditions for the two Duverger's Law equilibria to coexist: 


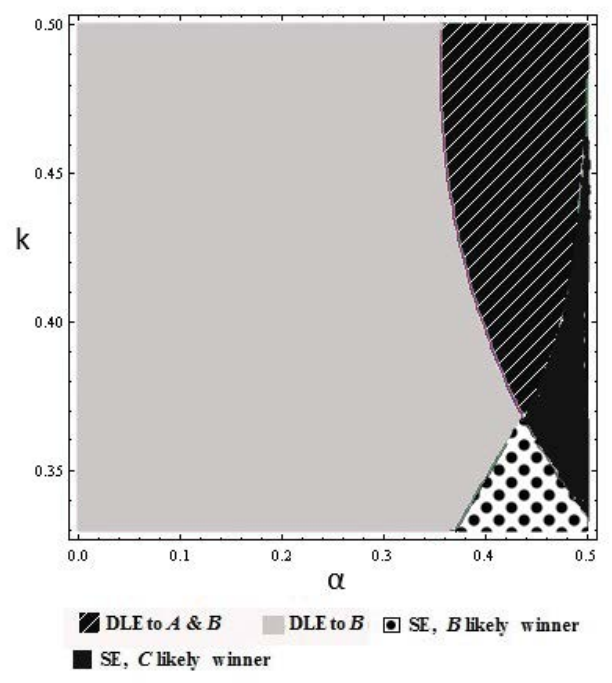

Figure 2: Equilibria with $\frac{W}{Y}=\frac{3}{4}$. The light colored area represents parameter values for which the unique equilibrium is the Duverger's Law equilibrium $(0,0)$, such that both types of voter vote for $B$. The striped area represents parameter values for which both Duverger's Law equilibrium $(0,0)$ and $(1,1)$ exist. The remaining areas represent parameter values for which the unique equilibrium is sincere voting, such that each voter type votes for their first choice, with the black area representing those values for which the Condorcet loser is the likely winner.

Proposition 5 If $W<Y$, then for $\alpha$ sufficiently large, $\exists \bar{k}$ (decreasing in $\alpha$ ) such that, if $k>\bar{k}$, both Duverger's Law equilibria exist under plurality.

Proposition 5 shows that both Duverger's Law equilibria exist when majority voters care relatively more about preventing the victory of the minority candidate than about electing their most-preferred majority candidate, and when the minority candidate is sufficiently strong. In such cases, even $b$-voters are willing to abandon their champion: this is the only way to defeat the minority candidate that they dislike a lot. Again, we can illustrate the result with a numerical example. To do so we produce Figure 2, which is similar to Figure 1 but for $\frac{W}{Y}=\frac{3}{4}$. Figure 2 clearly shows that the Duverger's law equilibria coexist only when $k$ is large enough. It also highlights that $\alpha$ must be large enough.

Together, Propositions 4 and 5 show a non-monotonicity with respect to $\alpha$. If $k$ is sufficiently large, then there will be equilibrium multiplicity (the two Duverger's Law equilibria) once the two groups become sufficiently evenly divided ( $\alpha$ large). However, if $k$ is sufficiently small, then a large $\alpha$ will lead to sincere voting. Similarly, there is a corresponding discontinuity with respect to $k$. If $\alpha$ is relatively evenly divided, when $k$ is small an increase in the size of the minority will still retain sincere voting as a unique equilibrium, while potentially making the Condorcet loser $C$ the likely winner. However, 
there exists a point at which it will shift the equilibrium to a Duverger's Law equilibrium, meaning there exists a point at which an increase in $k$ actually decreases the probability of $C$ winning by incentivizing strategic behavior on the part of the majority.

\section{$4 \quad$ Majority Runoff Elections}

In this section, we study the behavior of voters in majority runoff elections. Our main focus is on the comparison with the behavior in plurality elections. We also study a variant of the majority runoff rule in which more than two candidates are allowed in the second round if they obtain more than a pre-defined fraction of the registered voters. Due to its use in parliamentary and local elections in France, we call this variant of the majority runoff rule the "French-style runoff".

Under the majority runoff rule, there is up to two rounds of voting. In the first round, $(\rho=1)$, all voters are called to cast a ballot in favor of one of the candidates. The action set is denoted by $\Psi^{1}=\{A, B, C\}$. If the candidate who ranks first obtains more than $50 \%$ of the votes, she wins outright and there is no second round. Otherwise, there is a second round $(\rho=2)$ opposing the two candidates who received the most votes in the first round (the top-two candidates). In that round, voters are again called to cast a vote for one of the participating candidates. The action set is denoted by $\Psi^{2}=\{P, Q\}$, where $P$ and $Q$ refer to the candidates who ranked first and second in the first round, respectively. The candidate with the largest number of votes in that round wins the election.

Following Bouton (2013) and Bouton and Gratton (2015), we work under the assumption that the set of voters going to the polls in the first and second rounds may differ; in round $\rho$, voters of type $\theta \in \Theta$ turn out with an (exogenously given) probability $q_{\theta}^{\rho}$, drawn from a Uniform distribution with support $[0,1]$.

In the case of majority runoff, it proves useless to change the notation in order to accommodate for these more complex strategies. This is because majority voters have an obvious dominant strategy in every possible second round. It is thus not necessary to keep track of their strategy in that round. Instead, one can lighten notation by focusing on the behavior of voters in the first round. We denote by $\sigma_{i} \in[0,1]$ the probability that group $i$ votes for $A$ in the first round of a runoff election. 
There are three possible second rounds in majority runoff elections: $A$ vs. $B, A$ vs. $C$, and $B$ vs. $C$. When the second round pits one majority candidate against the minority candidate, both $a$-voters and $b$-voters strictly prefer to vote for the participating majority candidate. Otherwise, they increase the probability that their least-preferred candidate wins. For the same reason, when the second round features the two majority candidates, $a$-voters strictly prefer to vote for candidate $A$, and $b$-voters strictly prefer to vote for candidate $B$. It remains to be determined what $c$-voters do in that case. Given that they are indifferent between $A$ and $B$, we assume that they abstain. This is for the sake of simplicity: we can relax that assumption without affecting the results qualitatively.

To deal with potential issues of sequential rationality, we focus on (pure strategy) Weak Perfect Bayesian Equilibria (WPBE) ${ }^{28}$ A WPBE under majority runoff is a tuple $\left\{\sigma_{i}\right\}_{i=a, b}$ such that

$$
\begin{array}{lll}
\sigma_{a}^{*} & \text { maximizes } & p_{A}^{R}\left(\sigma_{a}, \sigma_{b}^{*}\right) W-\left(1-p_{A}^{R}\left(\sigma_{a}, \sigma_{b}^{*}\right)-p_{B}^{R}\left(\sigma_{a}, \sigma_{b}^{*}\right)\right) Y, \text { and } \\
\sigma_{b}^{*} \quad \text { maximizes } & p_{B}^{R}\left(\sigma_{a}^{*}, \sigma_{b}\right) W-\left(1-p_{A}^{R}\left(\sigma_{a}^{*}, \sigma_{b}\right)-p_{B}^{R}\left(\sigma_{a}^{*}, \sigma_{b}\right)\right) Y,
\end{array}
$$

where $p_{\psi}^{R}\left(\sigma_{a}, \sigma_{b}\right)$ is the probability that candidate $\psi$ wins when the strategy profile is $\left(\sigma_{a}, \sigma_{b}\right)$, and taking into account the dominant strategies in the second round. See the proof of Lemma 6 (in Appendix A5) for details about these probabilities.

The set of pure strategy WPBE majority under runoff share many features with the set of equilibria under plurality (see Appendix A5 for details): (i) the same two types of equilibria exist, (ii) the sincere voting equilibrium never coexists with a Duverger's law equilibrium, and (iii) the equilibrium is unique for a broad set of parameter values (either the sincere voting equilibrium, or the Duverger's law $(0,0)$ ). Yet, the conditions under which those different situations occur are different under plurality and runoff. In particular, we can prove that sincere voting is more prevalent under runoff than under plurality:

\footnotetext{
${ }^{28}$ Under plurality, the set of pure WPBE corresponds to the set of pure Bayesian equilibria.
} 
Proposition 6 Given a set of parameter values $W, Y, k$, and $\alpha$,

1. The sincere voting equilibrium always exists in the first round of a runoff election if it exists under plurality;

2. There exist a set of parameter values $W, Y, k$, and $\alpha$, such that the sincere voting equilibrium exists in the first round of a runoff election even if it does not exist under plurality.

This result is rather intuitive. Voters have weaker incentives to coordinate behind one of the majority candidates in the first round of a majority runoff election because the second round offers another opportunity for majority voters to defeat the minority candidate. She is thus less of a threat to majority voters, who then feel freer to vote for their most-preferred candidate in the first round. As discussed in the introduction, this result is in line with the findings of the empirical literature

\subsection{French-Style Runoff}

The French runoff system for parliamentary and local elections differs from the "standard" majority runoff system analyzed above. The difference is that, on top of the $50 \%$-threshold for first-round victory, it features another threshold at $12.5 \%$ of the registered voters: if a candidate finishes third (or lower), but receives more than that threshold number of votes, then she will also advance to the second round. In our setup, this opens the door for a second round with three candidates.

We consider any French-style runoff rule with a second-round qualification threshold $\tau \in(0,0.5)$. Under such a system, there are four possible second rounds: $A$ vs. $B$ or $C, B$ vs. $C$, and the opposition of all three candidates. The set of possible second round is thus $\{A B, A C, B C, A B C\}$. Given that a second round featuring three candidates is possible, it is important that strategies specify the actions played in each subgame. We thus have to adapt the notation. Yet, since majority voters have a dominant strategies in all second rounds involving two candidates, we only need to keep track of their strategy in the $A B C$

second round. We denote by $\sigma_{i}^{A B C} \in[0,1]$ the probability that group $i$ votes for $A$ in the $A B C$ second round. As before, we denote by $\sigma_{i} \in[0,1]$ the probability that group $i$ votes for $A$ in the first round of a runoff election. 
As under majority runoff, we focus on (pure strategy) WPBE. A WPBE under Frenchstyle runoff is a tuple $\left\{\sigma_{i}, \sigma_{i}^{A B C}\right\}_{i=a, b}$.

We start with the analysis of second-round voting behavior. When there are two candidates participating in the second round, the behavior of voters is the same as the one in the second round of a majority runoff election. When there are three candidates participating in the second round, voters behave as in a plurality election (see Propositions $1,2$, and 3$)$.

We are now in position to analyze the behavior of voters in the first round. We focus on the comparison with plurality and majority runoff. We can prove that sincere voting is more prevalent under French-style runoff than under plurality, but less prevalent under French-style runoff than under majority runoff:

Proposition 7 Given a set of parameter values $W, Y, k$, and $\alpha$ :

- if the sincere voting equilibrium exists under plurality, it also exists in the first round of a French-style runoff election, but the converse is not true;

- if the sincere voting equilibrium exists in the first round of a French-style runoff election, it is also an equilibrium in the first round of a majority runoff election, but the converse is not true

The intuition of the first part of the Proposition is the same as for majority runoff: voters have weaker incentives to coordinate behind one majority candidate in the first round of a french-style runoff election because the second round offers another opportunity for majority voters to defeat the minority candidate.

The second part of the Proposition is perhaps surprising. Even if it is easier for a candidate to qualify for the second round in a French-style runoff election than in a majority runoff election, voters are more inclined to abandon their preferred candidate in the former. This is so because, under French-style runoff, a majority candidate who qualified for a second round against the minority candidate is not guaranteed of the support of all majority voters. By sending one's preferred candidate to the second round, one may increase the risk that the minority candidate wins (if majority voters split their votes).

Proposition 7 is coherent with the empirical findings of Pons and Tricaud (2018). They find that the vote share of the top two candidates (as a percentage of the number of 
registered voters) is lower in second rounds with three candidates than with two candidates. This is due to the presence of so-called "switcher" voters, who vote for their preferred among the top two candidates when their most preferred candidate, the third one, does not participate in the second round, but vote for him when he does participate. This is exactly what our model predicts if one considers equilibria such that voters vote sincerely both in the first round and in the $A B C$ second round. ${ }^{29}$ In that case, the qualification of the third candidate to the second round leads to a substantial reduction in the vote share of the top two candidates. This is so because the supporters of the third candidate, say $A$, switch away from supporting the other majority candidate, say $B$, to instead support $A$, their preferred candidate. Interestingly, this means that Pons and Tricaud (2018)'s findings are coherent with all voters being (group-based) strategic.

Finally, Proposition 7 leads to the following extension:

Proposition 8 Under French-style runoff, the prevalence of sincere voting is increasing in the level of the threshold $\tau$.

This result is initially surprising. The common argument justifying the introduction of a second-round qualification threshold is that the purpose of such a threshold is to balance two desirable but contradictory characteristics of the electoral systems. On the one hand, a higher threshold is deemed desirable because, by reducing the number of candidates in the second round, it increases the likelihood that the victor is supported by a large plurality of the population. On the other hand, a higher threshold is deemed undesirable because it reduces the diversity of choices offered to voters in the second round. Therefore, the common belief is that this legitimacy vs. pluralism trade-off tilts in favor of legitimacy for higher thresholds, and in favor of pluralism for lower ones. Our result suggests that this trade-off may actually tilt in the exact opposite direction: by increasing the secondround qualification threshold, one may actually increase the probability of a second round featuring three candidates (because voters have stronger incentives to vote sincerely in the first round). Increasing the threshold then tilts the balance in favor of pluralism, not legitimacy.

\footnotetext{
${ }^{29}$ Proposition 7 implies that, if all voters are strategic, then Pons and Tricaud (2018)'s findings can be supported by our model only in that case. Indeed, given that the $A B C$ second round is identical in terms of strategic incentives to a plurality election, Proposition 7 implies that sincere voting in a second round opposing the three candidates is not coherent with the existence of a Duverger's law in the first round.
} 
Obviously, this reversal of the legitimacy vs. pluralism trade-off is empirically relevant only if a substantial fraction of the electorate are (group-based) strategic. Ultimately, it is thus an empirical question: how does an increase of the threshold influence the number of candidate participating in the second round? It should be possible to explore this question by exploiting the changes in the level of this threshold over the past 60 years in France. Since the beginning of the Fifth Republic in France, the second-round qualification threshold has raised significantly: from $5 \%$ in 1958, to $10 \%$ and then $12.5 \%$ since 1988 (with a one-election switch to proportional representation in 1986).

\section{Extensions}

\subsection{Preferences: Real Line}

In this section, we discuss the robustness of our results to a more sophisticated structure of preferences. We focus on the widely studied case of a unidimensional policy space: the candidates and the groups of voters are positioned along the real line. This is a quite flexible case that allows us to relax the assumptions that (i) $c$-voters are indifferent between $A$ and $B$, and (ii) majority voters have the exact same cardinal preferences.

Let us assume that the position of group- $a$ is identical to the position of candidate $A$, and similarly for the two other group-candidate pairs. The three positions are denoted by $x_{a}, x_{b}$, and $x_{c}$. These are the bliss points of the different types of voters. ${ }^{30}$ Voters' utility is decreasing in the absolute value of the distance between their bliss point and the position of the winning candidate. To ensures comparability with the baseline model where candidate $C$ is the Condorcet loser, we assume that $x_{a}=0, x_{b} \in(0,1 / 2)$, and $x_{c}=1$. This directly implies that $W_{a}=W_{b}=x_{b}=Y_{c}$ and $Y_{a}=W_{c}=1-x_{b}>1-2 x_{b}=Y_{b}$. Therefore, $c$-voters are not indifferent between $A$ and $B$ anymore (they prefer $B$ over $A$ ), and $a$-voters have a higher disutility for $C$ than $b$-voters. Finally, we keep the assumption that, together, $a$ - and $b$-voters form a majority, but that $c$-voters are sufficiently numerous (i.e. more than $1 / 3$ of the electorate) so that $C$ is a serious threat.

\footnotetext{
${ }^{30}$ We have also considered an extension of the model in which there is preference heterogeneity within groups. In particular, we considered a distribution of preferences within each group, such that $x_{i}^{a} \sim f_{a}[0,1]$ and $x_{i}^{b} \sim f_{b}[0,1]$, with $\frac{1}{2}>E\left[x_{i}^{b}\right]>E\left[x_{i}^{a}\right]$. Assuming that candidate $A$ 's ideal point is $E\left[x_{i}^{a}\right]$ and similarly for $B$ 's, we can show that heterogeneity within groups makes $a$-voters more inclined to vote sincerely. The effect on group $b$-voters depends on the specific shape of the preference distribution.
} 
First, we can prove that $c$-voters always prefer to vote for $C$ :

Lemma 3 Under plurality, in equilibrium, c-voters always vote for candidate $C$.

The intuition is as follows. For $c$-voters, the gain of voting for candidate $B$ instead of candidate $C$ is to avoid the victory of candidate $A$. The cost of voting for candidate $B$ is that their favorite candidate loses any chance of winning. Given that candidate $B$ is not very appealing to $c$-voters (because $x_{b} \in(0,1 / 2)$ ), and that candidate $A$ is relatively unlikely to win when $c$-voters vote sincerely (because $k>1 / 3$ ), $c$-voters have no incentive to vote for $B$.

Knowing that $c$-voters necessarily vote for $C$, we can fully characterize the set of equilibria:

Proposition 9 Under plurality:

- If $\frac{x_{b}}{p_{B}(1,1)-p_{A}(1,0)-p_{B}(1,0)}>\max \left\{\frac{1-x_{b}}{p_{A}(1,0)}, \frac{1}{p_{B}(1,0)}\right\}$, then sincere voting is the unique equilibrium,

- If $\frac{x_{b}}{p_{B}(1,1)-p_{A}(1,0)-p_{B}(1,0)} \in\left[\frac{1-x_{b}}{p_{A}(1,0)}, \frac{1}{p_{B}(1,0)}\right]$, then Duverger's law $(1,1)$ is the unique equilibrium,

- If $\frac{x_{b}}{p_{B}(1,1)-p_{A}(1,0)-p_{B}(1,0)} \in\left[\frac{1}{p_{B}(1,0)}, \frac{1-x_{b}}{p_{A}(1,0)}\right]$, then Duverger's law $(0,0)$ is the unique equilibrium,

- Otherwise, both Duverger law equilibria exist.

This proposition shows that our main results do not rely on $c$-voters being indifferent between $A$ and $B$, nor on majority voters having the exact same disutility of a victory of $C$. Even when these assumptions are relaxed, it remains true that (i) the sincere voting equilibrium never co-exists with a Duverger's law equilibrium, and (ii) that there exists a unique equilibrium for a broad set of parameter values. The features of the electoral environment that push toward sincere voting also remain the same.

An interesting implication of Proposition 9 is that the supporters of the centrist candidate (i.e. candidate $B$ ) are more "committed" to their most-preferred candidate than the other majority voters. In particular, if we were to swap the size of groups $a$ and $b$, 


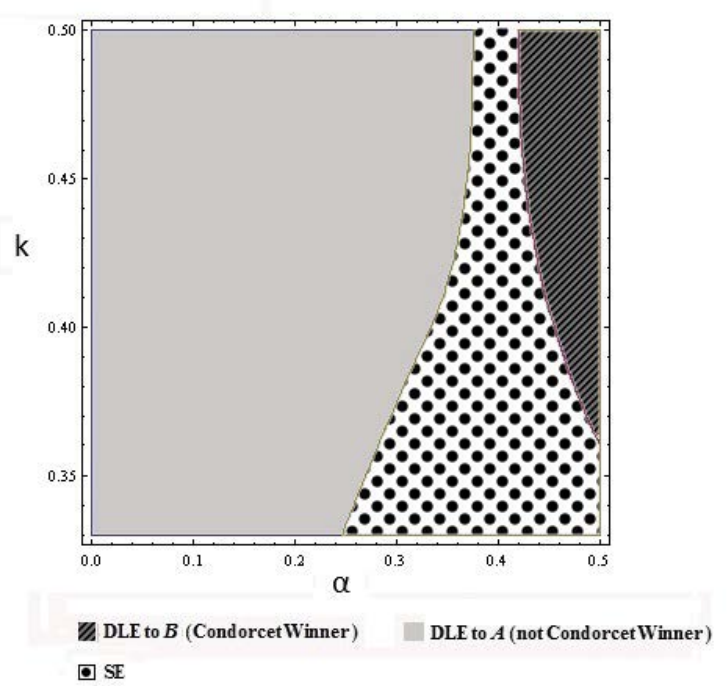

Figure 3: Equilibria with real line extension when $x_{b}=\frac{2}{5}$, and group $a$ (the left-wing group) is larger than group $b$ (the moderate group which supports the Condorcet winner); $\alpha$ represents the size of group $b$. The light colored area represents parameter values for which the unique equilibrium is the Duverger's Law equilibrium $(1,1)$, such that both types of voter vote for $A$. The dark striped area represents parameter values for which the unique equilibrium is the Duverger's Law equilibrium $(0,0)$, such that both types of voters vote for $B$. The remaining area represents parameter values for which the unique equilibrium is sincere voting, such that each voter type votes for their first choice.

keeping everything else constant, there would be cases such that all majority voters vote for candidate $B$ before the swap, but they all vote sincerely after the swap. By contrast, it is never the case that all majority voters vote for candidate $A$ before the swap, but then all vote sincerely after the swap. This result leads to the testable prediction that centrist voters should have a higher propensity to vote for their most-preferred candidate than other voters. Figure 3 shows how this changes the equilibria in the case where $x_{b}=\frac{2}{5}$.

\subsection{More Groups}

In this section, we explore the effect of the number of voting groups on the characteristics of the set of equilibria. The main message that stems out of this analysis is that the predictions of the group-based model of voting depend on the structure of group identity, i.e., the number and the types of groups.

\subsubsection{Group Splitting: Identical Subgroups}

We study how the size of the groups at which the voting decisions are made influences equilibrium behavior. To do so, we consider an extension of the model, such that the $a$ and $b$ groups are split into $n$ identical subgroups. Each group makes its own voting 
decision. The following Proposition shows that, for $n$ sufficiently large, the group-based voting model delivers the same set of equilibria as the pivotal voter model (without aggregate uncertainty, see Myerson and Weber 1993, Myerson 2002, Bouton, Castanheira and Llorente-Saguer 2017). This illustrates how the group-based voting model nests the pivotal voting model as a special case. ${ }^{31}$

Proposition 10 Under plurality, for $n$ sufficiently large:

- both Duverger's law equilibria exist for any values of $W, Y, k$, and $\alpha$;

- the sincere voting equilibrium never exists.

The intuition is exactly the same as under the pivotal voter model. Sincere voting is not an equilibrium because supporters of the weak majority candidate realize that the probability they make their favorite candidate win by voting for her is orders of magnitude smaller than the probability they make their second-preferred candidate win by voting for her. Thus, voting for their most-preferred candidate would be wasting a useful vote. Duverger's law equilibria exist for exactly the same reason.

As discussed in Grofman, Blais and Bowler (2009), some countries using plurality rule feature a stable two-party system (e.g., the US), while others do not (e.g. India). Proposition 10 suggests a novel explanation for such mixed empirical evidence about Duverger's law. Countries with stable two-party systems are those for which ethical groups are sufficiently fragmented. This prediction is not in contradiction with Duverger's original idea, which finds support in the data (Clark and Golder 2006), "[...] that social heterogeneity should increase the number of parties only once the electoral system is sufficiently permissive." (Clark and Golder 2006, p. 704). It actually refines it by suggesting that the nature of social heterogeneity is crucial: a fragmentation of groups with similar interests should have a negative effect on the number of "serious" candidates, whereas the fragmentation of society into more groups with different interests should have a positive effect.

\footnotetext{
${ }^{31}$ When $n$ grows large, the aggregate uncertainty in our model, which is at the subgroup level, vanishes. We would need uncertainty at the group level to maintain aggregate uncertainty when $n$ grows large.
} 


\subsubsection{One Group Per Preference Orderings}

We now consider a case with a group for each possible strict preference ordering. We denote the type of a voter by $i j$, where $i$ is the voter's first choice and $j$ is the voter's second choice. Therefore, a voter identified as type $a b$ features the ordering $A \succ B \succ C$. Let $\alpha_{i j}$ be the proportion of the population of type $i j$, such that $\sum \alpha_{i j}=1$. We keep the simplifying assumption that $W$ is utility if first-best win, 0 is utility for second-best, and $-Y$ is utility for third-best.

We use the following definition:

Definition 3 Let $v_{i j}$ be the vote total for voter type ij if everyone votes sincerely, such that $v_{i j}=\alpha_{i j} q_{i j}$.

A voter of type $i j$ will vote sincerely, given all other voters are voting sincerely, if and only if

$\frac{W}{Y} \geq \frac{\operatorname{Pr}\left[v_{k i}+v_{k j}>\max \left\{v_{i j}+v_{i k}, v_{j i}+v_{j k}\right\}\right]-\operatorname{Pr}\left[v_{k i}+v_{k j}>\max \left\{v_{j i}+v_{j k}+v_{i j}, v_{i k}\right\}\right]}{\operatorname{Pr}\left[v_{i j}+v_{i k}>\max \left\{v_{j i}+v_{j k}, v_{k i}+v_{k j}\right\}\right]-\operatorname{Pr}\left[v_{i k}>\max \left\{v_{j i}+v_{j k}+v_{i j}, v_{k i}+v_{k j}\right\}\right]}$

Equation (3) tells us that a group will vote sincerely if and only if the ratio between their gain from their first and second choice winning is greater than the ratio in the difference between their marginal impact on defeating their third-choice from voting strategically and their marginal impact on helping their first choice win by voting sincerely. This is a generalization of the equations in Proposition 1 and Proposition 3. Hence, a group still prefer to voter sincerely when there is a larger mass of other voters supporting their first choice than their second choice; otherwise, whether they vote sincerely depends upon their marginal utilities over the different candidates. ${ }^{32}$

\footnotetext{
${ }^{32}$ By the definition of vote totals, one can use a mathematical package such as Mathematica to show that the right hand side of equation (3) is decreasing in $\alpha_{i j}$ and $\alpha_{i k}$, increasing in $\alpha_{j i}$ and $\alpha_{j k}$, and increasing in $\alpha_{k i}$ and $\alpha_{k j}$. See the online appendix for the Mathematica code.
} 
Proposition 11 Under plurality, with a full type set, the sincere voting equilibrium exists if and only if

$\frac{W}{Y} \geq \max _{i j}\left\{\frac{\operatorname{Pr}\left[v_{k i}+v_{k j}>\max \left\{v_{i j}+v_{i k}, v_{j i}+v_{j k}\right\}\right]-\operatorname{Pr}\left[v_{k i}+v_{k j}>\max \left\{v_{j i}+v_{j k}+v_{i j}, v_{i k}\right\}\right]}{\operatorname{Pr}\left[v_{i j}+v_{i k}>\max \left\{v_{j i}+v_{j k}, v_{k i}+v_{k j}\right\}\right]-\operatorname{Pr}\left[v_{i k}>\max \left\{v_{j i}+v_{j k}+v_{i j}, v_{k i}+v_{k j}\right\}\right]}\right\}$

As in the standard framework, a sincere voting equilibrium will be most likely when all six types are relatively equal in size.

The addition of new groups with different preference orderings allow for a third type of equilibria, partial Duverger's law equilibria:

Definition 4 An equilibrium is a partial Duverger's law equilibrium if there exists some candidate $i$ such that voters in group ij vote sincerely (i.e., they vote for $i$ ), but voters in group ik do not vote sincerely (i.e., they vote for $k$ ); all other voters vote sincerely.

A partial Duverger's law equilibrium involves one candidate losing some, but not all, of her supporters to another candidate. Such an equilibrium is consistent with the findings of the empirical literature on strategic voting that partial coordination behind strong candidates occur in real-life and in the laboratory (e.g., Kawai and Watanabe 2015, Spenkuch 2018, Bouton et al. (2017), and references therein). The usual interpretation of that finding is that the electorate is composed of both strategic and non-strategic voters (a possibility we explore in Section 5.3). The following result suggests that such patterns in the data are consistent with all voters being (group-based) strategic:

Proposition 12 A partial Duverger's law equilibrium exists if and only if there exist some candidates $i, j, k$ such that

$$
\begin{aligned}
& \frac{W}{Y} \geq \frac{\operatorname{Pr}\left[v_{k i}+v_{k j}+\nu_{i k}>\max \left\{v_{i j}, v_{j i}+v_{j k}\right\}\right]-\operatorname{Pr}\left[v_{k i}+v_{k j}+\nu_{i k}>v_{j i}+v_{j k}+v_{i j}\right]}{\operatorname{Pr}\left[v_{i j}>\max \left\{v_{j i}+v_{j k}, v_{k i}+v_{k j}+v_{i k}\right\}\right]} \\
& \quad \text { and } \\
& \frac{W}{Y}<\frac{\operatorname{Pr}\left[v_{j i}+v_{j k}>\max \left\{v_{i j}+v_{i k}, v_{k i}+v_{k j}\right\}\right]-\operatorname{Pr}\left[v_{j i}+v_{j k}>\max \left\{v_{k i}+v_{k j}+v_{i k}, v_{i j}\right\}\right]}{\operatorname{Pr}\left[v_{i j}+v_{i k}>\max \left\{v_{j i}+v_{j k}, v_{k i}+v_{k j}\right\}\right]-\operatorname{Pr}\left[v_{i j}>\max \left\{v_{j i}+v_{j k}, v_{k i}+v_{k j}+v_{i k}\right\}\right]}
\end{aligned}
$$


The first condition in the proposition states that one of the groups $(i j)$ is large enough (and their third choice is weak enough) that even when other supporters of candidate $i$ (group $i k$ ) vote for $k$ (the least preferred option of $i j$-voters), they still prefer to hold onto the hope of getting their first choice over the line rather than voting for their second best. By contrast, the second condition implies that groupik is too small (and their third choice $j$ is strong enough), hence voters in that group do not want to vote sincerely, and instead prefer buttressing their first choice. Hence, we should see a mix of strategic and sincere voting among supporters of candidate $i$ when (i) most of candidate $i$ 's supporters agree on the second choice, (ii) the three candidates have relatively similar numbers of supporters, and (iii) candidate $k$ (the third-choice of most of $i$ 's supporters) is more popular than candidate $i$. Under these conditions, the small number of $i$ supporters who have $k$ as their second choice choose to vote strategically for $k$, as that increases the chance of defeating $j$ without affecting the probability of $i$ winning by much.

We can also show that a partial Duverger's law equilibrium never co-exists with some other types of equilibria:

Proposition 13 A partial Duverger's law equilibrium where i's supporters split their votes never co-exists with either a sincere voting equilibrium nor a Duverger's law equilibrium where candidate $i$ receives no votes.

Proposition 13 does not guarantee that equilibria with three serious candidates never co-exist with equilibria with two serious equilibria. Actually, that result proves fragile to an increase in the number of groups (with different preference orderings): there are cases in which the sincere voting equilibrium can coexist with Duverger's law equilibria. We illustrate this with an example. Suppose there are 4 groups with positive mass and the following preference orderings: $a b, b a, b c, c b$. We also let $\frac{W}{Y}=1, \alpha_{a b}=\alpha_{c b}=\frac{1}{3}$ and $\alpha_{b a}=\alpha_{b c}=\frac{1}{6}$. In this example, each candidate has identical first-choice support, but candidate $B$ has divided support between two groups. In this case, it is easy to see that neither "extreme" ( $a$ and $c$ ) group will want to deviate to supporting $b$ : voting sincerely defeats their respective third choices $\frac{2}{3}$ of the time, while coordination behind candidate $b$ increases the likelihood of defeating their respective third choice to $\frac{5}{6}$, but also removes the $\frac{1}{3}$ chance of their respective first choice winning. The ratio of the gain from coordination then is $\frac{\frac{1}{6}}{\frac{1}{3}}=\frac{1}{2}<1$. 
Now consider the "moderates" (groups $b a$ and $b c$ ): if they expect the other moderate group to vote sincerely, they also do so, as they have even less gain from coordination behind their second choice (as each subgroup represents only $\frac{1}{6}$ of the electorate) while still virtually guaranteeing a loss to their first choice by doing so. Hence, the sincere voting equilibrium exists. However, if they expect the other moderate group to coordinate behind their second choice, e.g., groups $a b$ and $b a$ voting for a, they have virtually no chance of electing their first choice (as they are $\frac{1}{6}$ of the population against $\frac{1}{3}$ and $\frac{1}{2}$ ) but can increase the chance of their second choice winning to $\frac{1}{2}$ by balancing the playing field. Hence, a Duverger's law equilibrium AC also exists. Group-based voting models cannot guarantee a unique prediction about the number of serious candidates when each candidate has relatively similar support, but at least one has support that is relatively equally divided among second choices.

As we discuss in the Introduction, the results in this section highlights the importance of the assumptions concerning the number of groups and their composition for the predictions of the group-based model of voting.

\subsection{Expressive Voters}

As mentioned above, the empirical literature on strategic voting (e.g., Kawai and Watanabe 2015, Spenkuch 2018, Bouton et al. (2017), and references therein) finds results coherent with the electorate being composed of both strategic and non-strategic voters. In this section, we explore the effect of the presence of expressive voters, who always vote sincerely for their most-preferred candidate, on the strategic behavior of other voters.

Let a share $\tau \in(0,1)$ of voters within the majority be expressive. The presence of expressive voters affects the necessary and sufficient condition for a sincere voting equilibrium to exist (as in the case without expressive voters, the sincere voting equilibrium never coexists with a Duverger's law equilibrium). In particular, under plurality, the sincere voting equilibrium exists if and only if :

$$
\frac{W}{Y} \geq \frac{p_{B}^{\tau}(0,0)+p_{A}^{\tau}(0,0)-p_{A}(1,0)-p_{B}(1,0)}{p_{A}(1,0)-p_{A}^{\tau}(0,0)}
$$

where $p_{j}^{\tau}\left(\lambda_{a}, \lambda_{b}\right)$ is the probability candidate $j$ wins if their is a fraction $\tau$ of expressive voters, and the other voters vote according to the strategy $\left(\lambda_{a}, \lambda_{b}\right)$. Obviously, when all 
strategic voters vote sincerely, i.e., $\left(\lambda_{a}, \lambda_{b}\right)=(1,0)$, the probabilities of victories of the different candidates are not affected by the fraction of expressive voters in the electorate, i.e., $p_{j}^{\tau}(1,0)=p_{j}(0,0) \forall j, \tau$.

Condition (4) shows that the presence of expressive voters has two impacts on the incentives of strategic voters. First, it reduces the value of coordinating behind one majority candidate: coordination among majority voters cannot be complete, hence candidate $C$ is less likely to be defeated $\left(p_{B}^{\tau}(0,0)+p_{A}^{\tau}(0,0)<p_{B}^{\tau}(0,0)\right)$. Second, it reduces the cost of coordination: even when all strategic voters abandon one of the majority candidates, there is still a chance that she wins due to the remaining expressive voters. Which effect dominates depends on the share of expressive voters in the electorate:

Proposition 14 There exists a $\hat{\tau}>0$ such that when $\tau<\hat{\tau}$, an increase in $\tau$ will increase the set of $k$ and $\alpha$ such that the sincere voting equilibrium exists. When $\tau>\hat{\tau}$, an increase in $\tau$ decreases the set of $k$ and $\alpha$ such that the sincere voting equilibrium exists. There is always a $\tau$ sufficiently large such that the sincere voting equilibrium does not exist.

This proposition shows that, perhaps surprisingly, (i) the presence of expressive voters has a non-monotonic effect on the existence of the sincere voting equilibrium, and (ii) when the share of expressive voters is sufficiently large, the sincere voting equilibrium does not exist.

We can also show that the presence of expressive voters reduces the incentives of $b$ voters to coordinate behind candidate $A$, the weak majority candidate:

Proposition 15 An increase in $\tau$ necessarily decreases the set of $k$ and $\alpha$ such that the Duverger's law equilibrium $(1,1)$ exists. There is always a $\tau$ sufficiently large such that the Duverger's law equilibrium $(1,1)$ does not exist.

Why is the effect of the presence of expressive voters monotonic for the Duverger's law equilibrium $(1,1)$, and not the other types of equilibria? This is so because, when the vote share of expressive voters is sufficiently large, $b$-voters voting for $A$ means dividing votes more evenly between majority candidates, and thus increasing the chance that candidate $C$ wins. By contrast, $a$-voters voting for $B$ always reinforces the most serious contender of candidate $C$. 
Together, Propositions 14 and 15 imply that, there is always a sufficiently large fraction of expressive voters such that the Duverger's law equilibrium $(0,0)$ is the unique equilibrium. Therefore, the inclusion of expressive voters in the group-based model of voting has the potential to make predictions crisper.

\section{Conclusions}

Our results display the strengths of the group-based model of voting: it is tractable, the predictions appear empirically sound and, due to equilibrium uniqueness for a broad set of parameter values, quite crisp. On the other hand, some results appear sensitive to the number and types of groups in the electorate. Hence, the way these groups form (which, in the real world, is endogenous to a number of the relevant parameters) are key to determine the behavior of voters in group-based models. Due to the crispness and soundness of the predictions that come from these models, understanding such group formation has great potential, but is unfortunately understudied (with one notable exception: Herrera and Martinelli 2006).

The existence of a unique equilibrium for a broad range of parameter values is an appealing feature of the group-based model of voting with multiple candidates. As we show in a companion paper (Bouton and Ogden 2018), this uniqueness opens the door for a tractable model including both strategic voters and strategic candidates. Such a model is valuable because understanding political institutions and their influence on policies requires a good understanding of the strategic behavior of politicians and voters, and how they interact. ${ }^{33}$ Yet most of the political economy literature focuses either on strategic candidates or strategic voters. For situations with more than two candidates, joint analyses are almost nonexistent. ${ }^{34}$ Indeed, the tractability and predictive power of extant models is affected by the existence of multiple equilibria at the voting stage. In Bouton and Ogden (2018), we revisit classic models of candidates behavior (entry and positioning along the real line) in a model with (group-based) strategic voters. We find that the presence of strategic voters dramatically affects the behavior of candidates.

\footnotetext{
${ }^{33}$ See the discussion in Myerson (1993).

${ }^{34}$ We are only aware of a handful of exceptions: Austen-Smith and Banks 1988, Myerson and Weber 1993, Besley and Coate 1997, Castanheira 2003, Dellis and Oak 2006, and Dellis 2009.
} 


\section{Appendices}

\section{Appendix A1: Preliminaries}

The following Lemma computes the probabilities of winning of the different candidates for all the possible pure strategy profiles.

Lemma 4 If $k>(1-\alpha)(1-k)$ (i.e., group $c$ is the largest), we have:

$$
\begin{aligned}
& p_{A}(1,0)=\frac{(1-k) \alpha^{2}}{3 k(1-\alpha)} \\
& p_{B}(1,0)=\frac{1-k}{2 k}\left[1-\alpha-\frac{1}{3(1-a)} \alpha^{2}\right] ; \\
& p_{A}(1,1)=p_{B}(0,0)=\frac{1}{2 k}\left[1-k-\frac{(1-2 k)^{3}}{3(1-\alpha) \alpha(1-k)^{2}}\right]
\end{aligned}
$$

If $k<(1-\alpha)(1-k)$ (i.e., group $b$ is the largest), we have:

$$
\begin{aligned}
& p_{A}(1,0)=\frac{(1-k) \alpha^{2}}{3 k(1-\alpha)} \\
& p_{B}(1,0)=\frac{3(2-3 k) k-\alpha^{2}(1-k)^{2}-6 \alpha(1-k) k}{6 k(1-\alpha)(1-k)} \\
& p_{A}(1,1)=p_{B}(0,0)=\frac{1}{2(1-\alpha)}\left[\frac{2-3 k}{(1-k)}-\alpha-\frac{\alpha^{2}(1-k)}{3 k}\right] .
\end{aligned}
$$

Proof. For a given strategy profile, the only uncertainty comes from the turnout of the different groups. The Lemma focuses on three strategy profiles: $(1,0)-$ i.e. group- $a$ votes for $A$ and group- $b$ votes for $B$, and $(1,1)$ or $(0,0)$-i.e. group- $a$ and group- $b$ vote for the same majority candidate (either $A(1,1)$ or $B(0,0))$.

First, let us consider the strategy profile $(1,0)$. Candidate $A$ wins if she obtains more votes than candidate $B$ (i.e. $q_{a}$ and $q_{b}$ are such that $\left.\alpha q_{a}>(1-\alpha) q_{b}\right)$ and more votes than candidate $C$ (i.e. $q_{a}$ and $q_{c}$ are such that $\left.(1-k) \alpha q_{a}>k q_{c}\right)$. Therefore, the probability that candidate $A$ wins for the strategy profile $(1,0)$ is:

$$
\begin{aligned}
p_{A}(1,0) & =\int_{0}^{1} \int_{0}^{\frac{\alpha}{1-\alpha} q_{a}} \int_{0}^{\frac{1-k}{k} \alpha q_{a}} \partial q_{c} \partial q_{b} \partial q_{a} \\
& =\frac{(1-k) \alpha^{2}}{3 k(1-\alpha)}
\end{aligned}
$$


The probability that candidate $B$ wins for the strategy profile $(1,0)$ depends on which of groups $b$ and $c$ is largest. If group- $c$ is the largest $(k>(1-\alpha)(1-k))$, then this probability is:

$$
\begin{aligned}
p_{B}(1,0) & =\int_{0}^{1} \int_{\frac{\alpha}{1-\alpha} q_{a}}^{1} \int_{0}^{\frac{1-k}{k}(1-\alpha) q_{b}} \partial q_{c} \partial q_{b} \partial q_{a} \\
& =\frac{1-k}{2 k}\left[1-\alpha-\frac{1}{3(1-a)} \alpha^{2}\right]
\end{aligned}
$$

If group- $b$ is the largest $(k<(1-\alpha)(1-k))$, this probability is more easily computed as $1-$ $p_{A}(1,0)-p_{C}(1,0)$. Therefore, we need $p_{C}(1,0)$, which is:

$$
\begin{aligned}
p_{C}(1,0) & =\int_{0}^{1} \int_{\frac{1-k}{k} \alpha q_{a}}^{1} \int_{0}^{\frac{k}{(1-k)(1-\alpha)} q_{c}} \partial q_{b} \partial q_{c} \partial q_{a} \\
& =\frac{1}{2(1-\alpha)}\left[\frac{k}{(1-k)}-\frac{\alpha^{2}(1-k)}{3 k}\right] .
\end{aligned}
$$

Thus, we have

$$
\begin{aligned}
p_{B}(1,0) & =1-\frac{(1-k) \alpha^{2}}{3 k(1-\alpha)}-\frac{1}{2(1-\alpha)}\left[\frac{k}{(1-k)}-\frac{\alpha^{2}(1-k)}{3 k}\right] \\
& =\frac{3(2-3 k) k-\alpha^{2}(1-k)^{2}-6 \alpha(1-k) k}{6 k(1-\alpha)(1-k)} .
\end{aligned}
$$

Second, let us consider the strategy profile $(1,1)$ (the $(0,0)$ case is identical). We are interested in the probability that the candidate supported by all majority voters, $A$ in the case under consideration), wins. This probability depends on which of groups $b$ and $c$ is largest. If group- $c$ is the largest, we can show that:

$$
p_{A}(1,1)=\frac{1}{2 k}\left[1-k-\frac{(1-2 k)^{3}}{3(1-\alpha) \alpha(1-k)^{2}}\right]
$$

If group- $b$ is the largest, then:

$$
p_{A}(1,1)=\frac{1}{2(1-\alpha)}\left[\frac{2-3 k}{(1-k)}-\alpha-\frac{\alpha^{2}(1-k)}{3 k}\right]
$$

The following Lemma proves that, when all voters vote sincerely, candidate $B$ is more likely to win than candidate $A$.

Lemma $5 p_{B}(1,0)>p_{A}(1,0)$.

Proof. Straightforward from Lemma 4. 


\section{Appendix A2: Proofs}

Proposition 1 Under plurality, the sincere voting equilibrium exists if and only if

$$
\frac{W}{Y} \geq \frac{p_{A}(1,1)-p_{A}(1,0)-p_{B}(1,0)}{p_{A}(1,0)}
$$

Proof. The strategy $(1,0)$ is an equilibrium under plurality if and only if neither group prefers voting for their second choice candidate. Formally, this requires

$$
p_{A}(1,0) W \geq\left(p_{B}(0,0)-1\right) Y+\left(1-p_{A}(1,0)-p_{B}(1,0)\right) Y
$$

for group $a$, and

$$
p_{B}(1,0) W \geq\left(p_{A}(1,1)-1\right) Y+\left(1-p_{A}(1,0)-p_{B}(1,0)\right) Y
$$

for group $b$. Given that $p_{A}(1,1)=p_{B}(0,0)$, the RHS of these two conditions are identical. From Lemma 5 , we have $p_{B}(1,0)>p_{A}(1,0)$. Therefore, condition (6) is necessarily satisfied when condition (5) is. The result follows from rearranging condition (5).

Lemma $1 \frac{p_{A}(1,1)-p_{A}(1,0)-p_{B}(1,0)}{p_{A}(1,0)}$ is increasing in $k$ and decreasing in $\alpha$.

Proof. Using Lemma 4 (in Appendix A1), we have that $\frac{p_{A}(1,1)-p_{A}(1,0)-p_{B}(1,0)}{p_{A}(1,0)}$ boils down to

$$
\frac{3}{2 \alpha}-\frac{(1-2 k)^{3}}{2 \alpha^{3}(1-k)^{3}}-2
$$

if $k>(1-\alpha)(1-k)$, and to

$$
\frac{3 k}{2(1-k) \alpha}-1
$$

if $k<(1-\alpha)(1-k)$.

Clearly, $\frac{3 k}{2(1-k) \alpha}-1$ is increasing in $k$ and decreasing in $\alpha$. It thus remains to prove that the same is true for $\frac{3}{2 \alpha}-\frac{(1-2 k)^{3}}{2 \alpha^{3}(1-k)^{3}}-2$. Taking the derivative with respect to $k$, we obtain

$$
\frac{3}{2 \alpha^{3}} \frac{(2 k-1)^{2}}{(k-1)^{4}}>0
$$

Taking the derivative with respect to $\alpha$, we obtain the following condition:

$$
\frac{3}{2 \alpha^{2}}\left[\frac{(1-2 k)^{3}}{\alpha^{2}(1-k)^{3}}-1\right]<0
$$


This simplifies to

$$
(1-2 k)^{3}<\alpha^{2}(1-k)^{3} .
$$

Since $\alpha>\frac{1-2 k}{1-k}$ in the relevant area, this is necessarily satisfied.

Proposition 2 Under plurality, there exists a Duverger's Law equilibrium $(0,0)$ if and only if

$$
\frac{W}{Y} \leq \frac{p_{A}(1,1)-p_{A}(1,0)-p_{B}(1,0)}{p_{A}(1,0)}
$$

Proof. Following a similar argument as the one in the proof of Proposition 1, we have that the strategy profile $(0,0)$ is an equilibrium if and only if

$$
p_{A}(1,0) W \leq\left(p_{B}(0,0)-1\right) Y+\left(1-p_{A}(1,0)-p_{B}(1,0)\right) Y
$$

It is obvious that group $b$ does not want to deviate. The result follows from rearranging the condition and using the equality $p_{B}(0,0)=p_{A}(1,1)$.

Proposition 3 Under plurality, there exists a Duverger's Law equilibrium $(1,1)$ if and only if

$$
\frac{W}{Y} \leq \frac{p_{A}(1,1)-p_{A}(1,0)-p_{B}(1,0)}{p_{B}(1,0)}
$$

Proof. The proof is similar to the proof of Proposition 2. The only difference is that we need to determine the condition for $b$-voters to prefer voting for $A$ (it is obvious that group $a$ does not want to deviate). Doing so, we have that the strategy profile $(1,1)$ is an equilibrium if and only if

$$
p_{B}(1,0) W \leq\left(p_{A}(1,1)-1\right) Y+\left(1-p_{A}(1,0)-p_{B}(1,0)\right) Y,
$$

The result follows from rearranging the condition.

Lemma $2 \frac{p_{A}(1,1)-p_{A}(1,0)-p_{B}(1,0)}{p_{B}(1,0)}$ is increasing both in $k$ and in $\alpha$.

Proof. $\frac{p_{A}(1,1)-p_{A}(1,0)-p_{B}(1,0)}{p_{B}(1,0)}$ can be re-written as $\frac{p_{A}(1,1)-p_{A}(1,0)}{p_{B}(1,0)}-1$.

The LHS can be re-written as $\frac{3(1-k)^{3}(1-\alpha) \alpha-2(1-k)^{3} \alpha^{3}-(1-2 k)^{3}}{\left[3(1-k)(1-\alpha)^{2}-(1-k) \alpha^{2}\right] \alpha(1-k)^{2}}$ if $k>(1-\alpha)(1-k)$.

Alternatively, it is $\frac{3(2-3 k) k-3 \alpha(1-k) k-3 \alpha^{2}(1-k)^{2}}{6(1-k) k(1-\alpha)-(1-k)^{2} \alpha^{2}-3 k^{2}}$ if $k<(1-\alpha)(1-k)$,

In both cases, the LHS is increasing in both $k$ and $\alpha$ :

In the first case, 


$$
\begin{aligned}
& \quad \frac{\partial}{\partial k}=\frac{\left(2\left(-(1-2 k)^{3}+3(1-a) a(1-k)^{3}-2 a^{3}(1-k)^{3}\right)\right)}{\left(a\left(3(1-a)^{2}(1-k)-a^{2}(1-k)\right)(1-k)^{3}\right)}+\frac{\left(6(1-2 k)^{2}-9(1-a) a(1-k)^{2}+6 a^{3}(1-k)^{2}\right)}{\left(a\left(3(1-a)^{2}(1-k)-a^{2}(1-k)\right)(1-k)^{2}\right)} \\
& -\frac{\left(\left(-3(1-a)^{2}+a^{2}\right)\left(-(1-2 k)^{3}+3(1-a) a(1-k)^{3}-2 a^{3}(1-k)^{3}\right)\right)}{\left(a\left(3(1-a)^{2}(1-k)-a^{2}(1-k)\right)^{2}(1-k)^{2}\right)} \text { and } \\
& \quad \frac{\partial}{\partial \alpha}=\frac{\left(3(1-a)(1-k)^{3}-3 a(1-k)^{3}-6 a^{2}(1-k)^{3}\right)}{\left(a\left(3(1-a)^{2}(1-k)-a^{2}(1-k)\right)(1-k)^{2}\right)}-\frac{\left((-6(1-a)(1-k)-2 a(1-k))\left(-(1-2 k)^{3}+3(1-a) a(1-k)^{3}-2 a^{3}(1-k)^{3}\right)\right)}{\left(a\left(3(1-a)^{2}(1-k)-a^{2}(1-k)\right)^{2}(1-k)^{2}\right)} \\
& \frac{\left(-(1-2 k)^{3}+3(1-a) a(1-k)^{3}-2 a^{3}(1-k)^{3}\right)}{\left(a^{2}\left(3(1-a)^{2}(1-k)-a^{2}(1-k)\right)(1-k)^{2}\right)} .
\end{aligned}
$$

In the second case,

$$
\frac{\partial}{\partial k}=\frac{-\left(\left(\left(6(1-a)(1-k)+2 a^{2}(1-k)-6 k-6(1-a) k\right)\left(-3 a^{2}(1-k)^{2}+3(2-3 k) k-3 a(1-k) k\right)\right)\right.}{\left.\left(-a^{2}(1-k)^{2}+6(1-a)(1-k) k-3 k^{2}\right)^{2}\right)}+\frac{\left(3(2-3 k)-3 a(1-k)+6 a^{2}(1-k)-9 k+3 a k\right)}{\left(-a^{2}(1-k)^{2}+6(1-a)(1-k) k-3 k^{2}\right)}
$$

and

$$
\frac{\partial}{\partial \alpha}=\frac{\left(\left(-2 a(1-k)^{2}-6(1-k) k\right)\left(-3 a^{2}(1-k)^{2}+3(2-3 k) k-3 a(1-k) k\right)\right)}{\left(-a^{2}(1-k)^{2}+6(1-a)(1-k) k-3 k^{2}\right)^{2}}+\frac{\left(-6 a(1-k)^{2}-3(1-k) k\right)}{\left(-a^{2}(1-k)^{2}+6(1-a)(1-k) k-3 k^{2}\right)} .
$$

One can check that these derivatives are all positive in the relevant ranges.

Proposition 4 If $W \geq Y$, then $\forall k, \alpha$ there exists a unique equilibrium under plurality. Moreover, $\exists \bar{\alpha}$ (increasing in $k$ ) such that, if $\alpha>\bar{\alpha}$, the unique equilibrium is the sincere voting equilibrium.

Proof. The first part of the proposition comes from the fact that $\frac{p_{A}(1,1)-p_{A}(1,0)-p_{B}(1,0)}{p_{B}(1,0)}$ is maximized at $k=\frac{1}{2}$ and $\alpha=\frac{1}{2}$ (from Lemma 2), where it takes the value $\frac{\frac{1}{2}-\frac{1}{6}-\frac{1}{6}}{\frac{1}{6}}=1$. Therefore, if $\frac{W}{Y}>1$, it is a dominant strategy for group $b$ to vote for $B$ for all $k$ and $\alpha$. The equilibrium is then uniquely pinned down by the behavior of group $a$.

The second part of the proposition is straightforward from Lemma 1. Recall that the condition for sincere voting is $\frac{W}{Y} \geq \frac{p_{A}(1,1)-p_{A}(1,0)-p_{B}(1,0)}{p_{A}(1,0)}$, the RHS of which is increasing in $k$ and decreasing in $\alpha$. Therefore, the necessary threshold $\bar{\alpha}$ is in turn increasing in $k$.

Lemma 5 If $W<Y$, then for $\alpha$ sufficiently large, $\exists \bar{k}$ (decreasing in $\alpha$ ) such that, if $k>\bar{k}$, both Duverger's Law equilibria exist under plurality.

Proof. This is direct from Lemma 2.

Proposition 6 Given a set of parameter values $W, Y, k$, and $\alpha$ :

- the sincere voting equilibrium always exists in the first round of a runoff election if it exists under plurality;

- the sincere voting equilibrium may exist in the first round of a runoff election even if it does not exist under plurality.

Proof. As shown in Proposition 17 (in Appendix A5), the necessary and sufficient condition for the existence of the sincere voting equilibrium under runoff is

$$
\frac{W}{Y} \geq \frac{p_{C}^{R}(1,0)-p_{C}^{R}(1,1)}{p_{A}^{R}(1,0)}
$$


To prove the first part of the proposition, we need to show that

$$
\frac{p_{C}(1,0)-p_{C}(1,1)}{p_{A}(1,0)} \geq \frac{p_{C}^{R}(1,0)-p_{C}^{R}(1,1)}{p_{A}^{R}(1,0)}
$$

First, note that $p_{C}^{R}(1,1)=p_{C}^{R}(0,0)=p_{C}(1,1)$. Indeed, when all majority voters vote for the same majority candidate, only two candidates receive a positive fraction of the votes. As a consequence, one of those two candidates must receive more than $50 \%$ of the votes, and win outright in the first round. As under plurality, the candidate receiving the largest number of votes in the first round wins the elections.

Second, we have from Lemma 6 (in Appendix A5) that, if $p_{A}^{R}(1,0)>p_{A}(1,0)$, then $p_{C}^{R}(1,0)<$ $p_{C}(1,0)$. Therefore, to show that condition (8) holds, it is sufficient to show that $p_{A}^{R}(1,0)>p_{A}(1,0)$ holds. Using Mathematica, we can see that this is true for $k>\frac{1}{3}$. Therefore, if parameter values are such that the sincere voting equilibrium exists (and it thus unique) under plurality, then it is also the unique equilibrium under runoff.

We know from Proposition 17 (in Appendix A5) that the necessary and sufficient condition for the existence of the Duverger's law equilibrium $(0,0)$ is the complement of condition $(7)$, we also have that if the Duverger's law equilibrium $(0,0)$ exists under runoff, then it also exists under plurality.

Given that condition (8) is satisfied with strict inequality, there exist a range of parameter values for which the sincere voting equilibrium is the unique equilibrium under runoff but it does not exist under plurality.

Proposition 7 Given a set of parameter values $W, Y, k$, and $\alpha$ :

- if the sincere voting equilibrium exists under plurality, it also exists in the first round of a French-style runoff election, but the converse is not true;

- if the sincere voting equilibrium exists in the first round of a French-style runoff election, it is also an equilibrium in the first round of a majority runoff election, but the converse is not true.

Proof. The proof of the first part is a straightforward extension of the proof of Proposition 6 .

The proof of the second part is in several steps. First, from the first part of the Proposition and from Proposition 6, we know that if a sincere voting equilibrium exists under plurality, it also exists under both majority runoff and French-style runoff; hence, if $\sigma_{a}^{A B C} \neq \sigma_{b}^{A B C}$, then sincere voting equilibrium exists under plurality, majority runoff, and French-style runoff.

Similarly, we know that Duverger's law equilibrium $(1,1)$ exists only if Duverger's law equilibrium $(0,0)$ exists, and $b$-voters have a stronger incentive to vote sincerely. Therefore, we only need to check the cases for which the Duverger's law equilibrium $(0,0)$ exists in the ABC second round, 
i.e. $\sigma_{a}^{A B C}=0=\sigma_{b}^{A B C}$ and $b$-voters vote sincerely in the first round.

In addition, for ease, define the following term:

Definition $\mathbf{5}$ Let $\boldsymbol{v}_{\boldsymbol{i}}$ be the (realized) vote total for group $i$ if everyone votes sincerely, such that $v_{a}=\alpha(1-k) q_{a}$ and $v_{b}=(1-\alpha)(1-k) q_{b}$.

When $\sigma_{a}^{A B C}=0=\sigma_{b}^{A B C}$, the sincere voting equilibrium exists under majority runoff if and only if

$$
\frac{W}{Y}>\frac{\operatorname{Pr}\left(v_{c} \in\left(\min \left\{v_{a}, v_{b}\right\}, v_{a}+v_{b}\right)\right)(1-p(0,0)}{\operatorname{Pr}\left(v_{a}>v_{b}+v_{c}\right)+\operatorname{Pr}\left(v_{b}+v_{c}>v_{a}>v_{b}<v_{c}\right) p(0,0)+\operatorname{Pr}\left(v_{b}+v_{c}>v_{a}>v_{c}<v_{b}\right) \frac{\alpha}{2(1-\alpha)}} .
$$

The sincere voting equilibrium exists under French-style runoff if and only if

$$
\frac{W}{Y}>\frac{\operatorname{Pr}\left(v_{c} \in\left(\min \left\{v_{a}, v_{b}, \tau\right\}, v_{a}+v_{b}\right)\right)(1-p(0,0))}{\operatorname{Pr}\left(v_{a}>v_{b}+v_{c}\right)+\operatorname{Pr}\left(v_{b}+v_{c}>v_{a}>v_{b}<\min \left\{v_{c}, \tau\right\}\right) p(0,0)+\operatorname{Pr}\left(v_{b}+v_{c}>v_{a}>v_{c}<\min \left\{v_{b}, \tau\right\}\right) \frac{\alpha}{2(1-\alpha)}} .
$$

Note that $\operatorname{Pr}\left(v_{c} \in\left(\min \left\{v_{a}, v_{b}, \tau\right\}, v_{a}+v_{b}\right)\right)>\operatorname{Pr}\left(v_{c} \in\left(\min \left\{v_{a}, v_{b}\right\}, v_{a}+v_{b}\right)\right)$, and hence the numerator (the change in probability of $C$ winning between strategic and sincere in the first round) is greater under French-style runoff, since $C$ now only needs to beat the threshold to get a 2nd chance in the 2 nd round.

In addition, note that $\operatorname{Pr}\left(v_{b}+v_{c}>v_{a}>v_{b}<\min \left\{v_{c}, \tau\right\}\right)<\operatorname{Pr}\left(v_{b}+v_{c}>v_{a}>v_{b}<v_{c}\right)$ and $\operatorname{Pr}\left(v_{b}+v_{c}>v_{a}>v_{c}<\min \left\{v_{b}, \tau\right\}\right)<\operatorname{Pr}\left(v_{b}+v_{c}>v_{a}>v_{c}<v_{b}\right)$, meaning the denominator (the probability of $A$ winning if sincere in the first round) is smaller under French-style runoff, since candidate $A$ only receives votes in the second round if it is a two-candidate outcome, and that is now less likely due to the threshold.

Therefore, there exists a range of parameter values for which the sincere voting equilibriun exists under majority runoff, but the Duverger's law equilibria are the only potential equilibria under French-style runoff.

Proposition 8 Under French-style runoff, the prevalence of sincere voting is increasing in the level of the threshold $\tau$.

\section{Proof.}

$\operatorname{Pr}\left(v_{c} \in\left(\min \left\{v_{a}, v_{b}, \tau\right\}, v_{a}+v_{b}\right)\right)$ is decreasing in the threshold $\tau$, meaning the numerator of equation 10 is decreasing.

$\operatorname{Pr}\left(v_{b}+v_{c}>v_{a}>v_{b}<\min \left\{v_{c}, \tau\right\}\right)$ and $\operatorname{Pr}\left(v_{b}+v_{c}>v_{a}>v_{c}<\min \left\{v_{b}, \tau\right\}\right)$ are increasing in $\tau$, meaning the denominator in equation 10 is increasing. 
Therefore, by equation 10, the prevalence of sincere voting is increasing in the level of the threshold $\tau$.

Proposition 3 Under plurality, in equilibrium, $c$-voters always vote for candidate $C$.

Proof. $\frac{W_{C}}{Y_{C}}=\frac{1-x_{b}}{x_{b}}>1$.

For a $c$-voter to vote for $B$, we need:

$$
\frac{W_{C}}{Y_{C}}<\frac{\operatorname{Prob}\left[v_{a}>\max \left\{v_{b}, v_{c}\right\}\right]-\operatorname{Prob}\left[v_{a}>v_{b}+v_{c}\right]}{\operatorname{Prob}\left[v_{c}>\max \left\{v_{a}, v_{b}\right\}\right]}
$$

By assumption of a credible threat, $k \geq(1-k) \alpha$. Therefore, $\operatorname{Prob}\left[v_{a}>\max \left\{v_{b}, v_{c}\right\}\right] \leq$ $\operatorname{Prob}\left[v_{c}>\max \left\{v_{a}, v_{b}\right\}\right]$. The RHS of equation 11 is less than one, and hence the condition can never hold.

Proposition 9 Under plurality:

- If $\frac{x_{b}}{p_{B}(1,1)-p_{A}(1,0)-p_{B}(1,0)}>\max \left\{\frac{1-x_{b}}{p_{A}(1,0)}, \frac{1}{p_{B}(1,0)}\right\}$, then sincere voting is the unique equilibrium,

- If $\frac{x_{b}}{p_{B}(1,1)-p_{A}(1,0)-p_{B}(1,0)} \in\left[\frac{1-x_{b}}{p_{A}(1,0)}, \frac{1}{p_{B}(1,0)}\right]$, then Duverger's law $(1,1)$ is the unique equilibrium,

- If $\frac{x_{b}}{p_{B}(1,1)-p_{A}(1,0)-p_{B}(1,0)} \in\left[\frac{1}{p_{B}(1,0)}, \frac{1-x_{b}}{p_{A}(1,0)}\right]$, then Duverger's law $(0,0)$ is the unique equilibrium,

- Otherwise, both Duverger law equilibria exist.

Proof. Straightforward extension of the baseline case.

Proposition 10 Under plurality, for $n$ sufficiently large:

- both Duverger's law equilibria exist for any values of $W, Y, k$, and $\alpha$;

- the sincere voting equilibrium never exists.

Proof. The existence of the Duverger's law equilibrium in which all voters voter for the same majority candidate, say $A$, is trivial to prove. If all $n-1$ other $b$-groups are voting for candidate A (hence all $a$-groups must also be voting for $A$ ), candidate $B$ wins if and only if the following condition is satisfied.

$$
\frac{1}{n}(1-k)(1-\alpha) q_{b}>\frac{n-1}{n}(1-k)(1-\alpha) q_{b}+(1-k) \alpha q_{a} .
$$


But, for $n$ sufficiently large, this condition cannot be satisfied. Hence, there is no incentive to vote for $B$.

Sincere voting is an equilibrium only if the following condition is satisfied (it guarantees that $a$-voters prefer to vote for $a$ when they expect other voters to vote sincerely):

$\frac{W}{Y}>\frac{P\left(v_{c}>\max \left\{(1-k)(1-\alpha) q_{b},(1-k) \alpha q_{a}\right\}\right)-P\left(v_{c}>\max \left\{(1-k)\left((1-\alpha) q_{b}+\frac{1}{n} \alpha q_{a}\right), \frac{n-1}{n}(1-k) \alpha q_{a}\right\}\right)}{P\left(\frac{n-1}{n}(1-k) \alpha q_{a} \in\left[\max \left\{(1-k)\left((1-\alpha) q_{b}-\frac{1}{n} \alpha q_{a}, v_{c}-\frac{1}{n} \alpha q_{a}\right\}, \max \left\{(1-k)\left((1-\alpha) q_{b}+\frac{1}{n} \alpha q_{a}, v_{c}\right\}\right]\right)\right.\right.}$.

It is easy to see that the right hand side tends to infinity when $n$ grows large due to the convexity of the probabilities. Therefore, for $n$ sufficiently large, this condition cannot be satisfied.

Proposition 13: A partial Duverger's law equilibrium where candidate $i^{\prime} s$ groups split never co-exists with either a sincere voting equilibrium nor a Duverger's law equilibrium where candidate $i$ receives no votes.

Proof. Let a partial Duverger's law equilibrium away from $i$ exists. By proposition 12's first equation, we know that $i j$ voters prefer to vote for candidate $i$ even when $i k$ voters are voting for candidate $k$. This directly rules out a Duverger's law equilibrium in which voters all vote for $j$ or $k$.

Proposition 12's second equation is just the flip of equation (3), ruling out a sincere voting equilibrium.

\section{Appendix A3: Mixed Strategy Equilibrium}

Concerning the mixed strategy, recall that such a mix would need to involve both groups being indifferent between voting sincerely or strategically. This is because if one group is playing a pure strategy, there generically exists a pure strategy best response (see sections 3.1 and 3.2 ).

In addition, the mixed strategy will only occur when $\frac{W}{Y} \leq \frac{p_{A}(1,1)-p_{A}(1,0)-p_{B}(1,0)}{p_{B}(1,0)}$ (i.e., when both Duverger's law equilibria exist); otherwise, $b$-voters have a dominant strategy to vote for sincerely regardless of $a$ 's behavior.

Formally, a mixed strategy for $a$-voters this involves $\sigma_{b}\left(W p_{A}(1,0)-Y\left(1-p_{A}(1,0)-\right.\right.$ $\left.\left.p_{B}(1,0)\right)\right)+\left(1-\sigma_{b}\right)\left(W p_{A}(1,1)-Y\left(1-p_{A}(1,1)\right)\right)=\sigma_{b}\left(-Y\left(1-p_{A}(1,1)\right)\right)+\left(1-\sigma_{B}\right)\left(W p_{B}(1,0)-\right.$ $\left.Y\left(1-p_{A}(1,0)-p_{B}(1,0)\right)\right)$, where $\sigma_{i}$ is the probability that group $i$ votes sincerely.

Note that this simplifies to $\sigma_{B}\left(W\left(p_{A}(1,1)-p_{A}(1,0)-p_{B}(1,0)\right)+2 Y\left(p_{A}(1,1)-p_{A}(1,0)-\right.\right.$ $\left.\left.p_{B}(1,0)\right)\right)=W\left(p_{A}(1,1)-p_{B}(1,0)\right)+Y\left(p_{A}(1,1)-p_{A}(1,0)-p_{B}(1,0)\right.$.

Therefore, a mixed strategy equilibrium involves $\sigma_{b}=\frac{W\left(p_{A}(1,1)-p_{B}(1,0)\right)+Y\left(p_{A}(1,1)-p_{A}(1,0)-p_{B}(1,0)\right)}{\left(p_{A}(1,1)-p_{A}(1,0)-p_{B}(1,0)\right)(W+2 Y)}$ 
and $1-\sigma_{b}=\frac{\left(p_{A}(1,1)-p_{A}(1,0)-p_{B}(1,0)\right) Y-p_{A}(1,0) W}{\left(p_{A}(1,1)-p_{A}(1,0)-p_{B}(1,0)\right)(W+2 Y)}$.

Similarly, $\sigma_{a}=\frac{W\left(p_{A}(1,1)-p_{A}(1,0)\right)+Y\left(p_{A}(1,1)-p_{A}(1,0)-p_{B}(1,0)\right)}{\left(p_{A}(1,1)-p_{A}(1,0)-p_{B}(1,0)\right)(W+2 Y)}, 1-\sigma_{a}=\frac{\left(p_{A}(1,1)-p_{A}(1,0)-p_{B}(1,0)\right) Y-p_{B}(1,0) W}{\left(p_{A}(1,1)-p_{A}(1,0)-p_{B}(1,0)\right)(W+2 Y)}$

Hence, we have the following proposition:

Proposition 16 Under plurality, if $\frac{W}{Y} \leq \frac{p_{A}(1,1)-p_{A}(1,0)-p_{B}(1,0)}{p_{B}(1,0)}$, there exists a mixedstrategy equilibrium with a voters voting sincerely with probability $\frac{W\left(p_{A}(1,1)-p_{A}(1,0)\right)+Y\left(p_{A}(1,1)-p_{A}(1,0)-p_{B}(1,0)\right)}{\left(p_{A}(1,1)-p_{A}(1,0)-p_{B}(1,0)\right)(W+2 Y)}$ and $b$ voters voting sincerely with probability $\frac{W\left(p_{A}(1,1)-p_{B}(1,0)\right)+Y\left(p_{A}(1,1)-p_{A}(1,0)-p_{B}(1,0)\right)}{\left(p_{A}(1,1)-p_{A}(1,0)-p_{B}(1,0)\right)(W+2 Y)}$.

Therefore, a mixed strategy equilibrium must involve the larger group (in this case, b) voting strategically at a higher rate than the smaller group. This result is a less stark form of what is found in a standard pivotal voting model (see, e.g., Myerson and Weber 1993). In the pivotal voting model, the larger majority group is the only one mixing, while the smaller group votes sincerely. In the group-based voting model, by comparison, the larger group must vote sincerely at a lesser rate than the smaller group, but still will vote sincerely more than half of the time. The requirement that the larger group vote strategically at a greater rate comes directly from the fact that the smaller group needs more support to be willing to consider voting sincerely, and hence exists in both models; however, this type of coordination breakdown in the ethical voting model can only occur when both groups are still more likely to vote sincerely. Note that this means it is possible for the Condorcet loser to be more likely to win than in the world with a unique equilibrium if this mixed strategy equilibrium occurs.

\section{Appendix A4: Majority Runoff}

Note that in general terms, the decision of whether to vote sincerely is the same under both plurality and runoff. Therefore,

Proposition 17 Under runoff, the sincere voting equilibrium exists if and only if $\frac{W}{Y} \geq$ $\frac{p_{A}^{R}(1,1)-p_{A}^{R}(1,0)-p_{B}^{R}(1,0)}{p_{A}^{R}(1,0)}$. Otherwise, the Duverger's law equilibrium $(0,0)$ exists.

Proof. Direct from $\sigma_{A}^{*}$ and $\sigma_{B}^{*}$, and the fact that $p_{A}^{R}(1,0)<p_{B}^{R}(1,0)$.

The condition in Proposition 17 can be re-written in terms of probabilities in the two rounds:

$\frac{W}{Y} \geq \frac{\left(\operatorname{Prob}\left[\frac{k}{1-k} q_{c}>\alpha q_{a}+(1-\alpha) q_{b}\right]+\operatorname{Prob}\left[\frac{k}{1-k} q_{c} \in\left(\min \left\{\alpha q_{a},(1-\alpha) q_{b}\right\}, \alpha q_{a}+(1-\alpha) q_{b}\right] \operatorname{Prob}\left[\frac{k}{1-k} q_{c}>\alpha q_{a}+(1-\alpha) q_{b}\right]\right)-\operatorname{Prob}\left[\frac{k}{1-k} q_{c}>\alpha q_{a}+(1-\alpha) q_{b}\right]\right.}{\operatorname{Prob}\left[\alpha q_{a}>\frac{k}{1-k} q_{c}+(1-\alpha) q_{b}\right]+\operatorname{Prob}\left[\alpha q_{a} \in\left(\min \left\{\frac{k}{1-k} q_{c},(1-\alpha) q_{b}\right\}, \frac{k}{1-k} q_{c}+(1-\alpha) q_{b}\right)\right] \operatorname{Prob}\left[\alpha q_{a}>\frac{k}{1-k} q_{c}+(1-\alpha) q_{b}\right]}$, 
and thus

$$
\frac{W}{Y} \geq \frac{\operatorname{Prob}\left[\frac{k}{1-k} q_{c} \in\left(\min \left\{\alpha q_{a},(1-\alpha) q_{b}\right\}, \alpha q_{a}+(1-\alpha) q_{b}\right]\right.}{1+\operatorname{Prob}\left[\alpha q_{a} \in\left(\min \left\{\frac{k}{1-k} q_{c},(1-\alpha) q_{b}\right\}, \frac{k}{1-k} q_{c}+(1-\alpha) q_{b}\right)\right]} \frac{\operatorname{Prob}\left[\frac{k}{1-k} q_{c}>\alpha q_{a}+(1-\alpha) q_{b}\right]}{\operatorname{Prob}\left[\alpha q_{a}>\frac{k}{1-k} q_{c}+(1-\alpha) q_{b}\right]}
$$

There are two comments about this simplification. First, these probabilities can be written in terms of the fundamentals $\alpha$ and $k$ in the same way as under plurality. For expositional clarity, we will not do so here. Second, this formulation leads to the following lemma:

Lemma 6 If $p_{A}^{R}(1,0)>p_{A}(1,0)$, then $p_{B}^{R}(1,0)>p_{B}(1,0)$.

\section{Proof.}

First, note that $p_{A}^{R}(1,0)=\left(1+\operatorname{Prob}\left[\alpha q_{a} \in\left(\min \left\{\frac{k}{1-k} q_{c},(1-\alpha) q_{b}\right\}, \frac{k}{1-k} q_{c}+(1-\alpha) q_{b}\right)\right]\right) \operatorname{Prob}\left[\alpha q_{a}>\right.$ $\left.\frac{k}{1-k} q_{c}+(1-\alpha) q_{b}\right]$.

Meanwhile, $p_{A}(1,0)=\operatorname{Prob}\left[\alpha q_{a}>\frac{k}{1-k} q_{c}+(1-\alpha) q_{b}\right]+\operatorname{Prob}\left[\alpha q_{a} \in \max \left\{\frac{k}{1-k} q_{c},(1-\alpha) q_{b}\right\}, \frac{k}{1-k} q_{c}+\right.$ $\left.(1-\alpha) q_{b}\right]$.

Therefore, the relevant inequality can be re-written as: $\operatorname{Prob}\left[\alpha q_{a} \in\left(\min \left\{\frac{k}{1-k} q_{c},(1-\alpha) q_{b}\right\}, \frac{k}{1-k} q_{c}+\right.\right.$ $\left.\left.(1-\alpha) q_{b}\right)\right] \operatorname{Prob}\left[\alpha q_{a}>\frac{k}{1-k} q_{c}+(1-\alpha) q_{b}\right]>\operatorname{Prob}\left[\alpha q_{a} \in \max \left\{\frac{k}{1-k} q_{c},(1-\alpha) q_{b}\right\}, \frac{k}{1-k} q_{c}+(1-\alpha) q_{b}\right]$.

Now consider the following for $B: \operatorname{Prob}\left[(1-\alpha) q_{b} \in\left(\min \left\{\frac{k}{1-k} q_{c}, \alpha q_{a}\right\}, \frac{k}{1-k} q_{c}+\alpha q_{a}\right)\right] \operatorname{Prob}[(1-$ $\left.\alpha) q_{b}>\frac{k}{1-k} q_{c}+\alpha q_{a}\right]>\operatorname{Prob}\left[(1-\alpha) q_{b} \in \max \left\{\frac{k}{1-k} q_{c}, \alpha q_{a}\right\}, \frac{k}{1-k} q_{c}+\alpha q_{a}\right]$.

As $1-\alpha>\alpha$, the left-hand side of this equation is larger than $B$, while the right-hand side is smaller.

Therefore, if the condition holds for $A$, it also holds for $B$.

A corollary of this lemma is that, if $p_{A}^{R}(1,0)>p_{A}(1,0)$, then $p_{C}^{R}(1,0)<p_{C}(1,0)$.

\section{References}

[1] Ali, N. and C. Lin (2013), Why People Vote: Ethical Motives and Social Incentives, 5(2): 73-98.

[2] Alvarez, M. and J. Nagler (2000). A New Approach for Modelling Strategic Voting in Multiparty Elections, British Journal of Political Science, 30(1): 57-75.

[3] Battaglini, M., R. Morton and T. Palfrey (2008), Information Aggregation and Strategic Abstention in Large Laboratory Elections, American Economic Review, Papers E Proceedings, 98(2): 194-200. 
[4] Battaglini, M., Morton, R. and T. Palfrey (2010), The Swing Voter's Curse in the Laboratory, Review of Economic Studies, 77: 61-89.

[5] Bhattacharya, S., J. Duffy and S. T. Kim (2014). Compulsory versus Voluntary Voting: An Experimental Study, Games and Economic Behavior, 84, 111--131.

[6] Blais, A., R. Nadeau, E. Gidengil, and N. Nevitte (2001). Measuring Strategic Voting in Multiparty Plurality Elections, Electoral Studies, 20(3): 343-352.

[7] Bordignon, M., T. Nannicini, and G. Tabellini (2016). Moderating Political Extremism: Single Round vs. Runoff Elections under Plurality Rule, American Economic Review, 106: 2348-2370.

[8] Bormann, N.-C., and M. Golder (2013). Democratic Electoral Systems around the world, 1946--2011, Electoral Studies, 32(2), 360--369.

[9] Bouton, L. (2013), A Theory of Strategic Voting in Runoff Elections, American Economic Review, 103(4): 1248-1288.

[10] Bouton, L., and M. Castanheira (2012), One Person, Many Votes: Divided Majority and Information Aggregation, Econometrica, 80(1): 43--87.

[11] Bouton, L., M. Castanheira, and A. Llorente-Saguer (2016), Divided Majority and Information Aggregation: Theory and Experiment, Journal of Public Economics, 134: 114-128.

[12] Bouton, L., M. Castanheira, and A. Llorente-Saguer (2017), Multicandidate Elections: Aggregate Uncertainty in the Laboratory, Games and Economic Behavior, 101: 132150.

[13] Bouton, L., and G. Gratton (2015), Majority Runoff Elections: Strategic Voting and Duverger's Hypothesis. Theoretical Economics, 10(2), 283-314.

[14] Bouton, L., A. Llorente-Saguer, and F. Malherbe (2017), Unanimous Rules in the Laboratory, Games and Economic Behavior, 102: 179-198.

[15] Bouton, L. and B. Ogden (2018). Strategic Candidates with Group-based Voting, Mimeo. 
[16] Callander, S. (2005). Duverger's Hypothesis, the Run-Off Rule, and Electoral Competition, Political Analysis, 13, pp. 209-232.

[17] Clark, W. and M. Golder (2006). Rehabilitating Duverger's Theory: Testing the Mechanical and Strategic Modifying Effects of Electoral Laws, Comparative Political Studies, 39: 679-708.

[18] Coate, S. and M. Conlin (2004). A Group Rule-Utilitarian Approach to Voter Turnout: Theory and Evidence, American Economic Review, 94(5): 1476-1504.

[19] Coate, S., M. Conlin, and A. Moro (2008). The Performance of Pivotal-Voter Models in Small-Scale Elections: Evidence from Texas Liquor Referenda, Journal of Public Economics, 92(3-4): 582-596.

[20] Cox, G. (1997), Making Votes Count, Cambridge, UK: Cambridge University Press.

[21] Dewan, T. and D. Myatt (2007), Leading the Party: Coordination, Direction, and Communication, American Political Science Review, 101(4): 825-843.

[22] Duverger, M. (1954). Political Parties. New York: John Wiley \& Sons.

[23] Feddersen, T. (2004), Rational Choice Theory and the Paradox of Not Voting, Journal of Economic Perspectives, 18: 99-112.

[24] Feddersen, T., S. Gailmard, and A. Sandroni (2009). Moral Bias in Large Elections: Theory and Experimental Evidence, American Political Science Review, 103(2): 175192.

[25] Feddersen, T. and A. Sandroni (2006a), A Theory of Participation in Elections, American Economic Review, 96(4): 1271-1282.

[26] Feddersen, T. and A. Sandroni (2006b), The Calculus of Ethical Voting, International Journal of Game Theory, 35: 1-25.

[27] Fey, M. (1997), Stability and Coordination in Duverger's Law: A Formal Model of Pre-election Polls and Strategic Voting, American Political Science Review, 91(1): $135-147$. 
[28] Fiorina, M. (1989), Retrospective Voting in American National Elections. Yale University Press, New Haven.

[29] Fisher, S. and D. Myatt (2001), Strategic Voting Experiments, mimeo, University of Oxford.

[30] Fisher, S. and D. Myatt (2014), Strategic Voting in Plurality Rule Elections, mimeo, London Business School.

[31] Forsythe, R., R. Myerson, T. Rietz and R. Weber (1993), An Experiment on Coordination in Multi-Candidate Elections: The Importance of Polls and Election Histories, Social Choice and Welfare, 10: 223-247.

[32] Forsythe, R., R. Myerson, T. Rietz and R. Weber (1996), An Experimental Study of Voting Rules and Polls in Three-Way Elections, International Journal of Game Theory, 25: 355-383.

[33] Fujiwara, T. (2011), A Regression Discontinuity Test of Strategic Voting and Duverger's Law, Quarterly Journal of Political Science, 6: 197-233.

[34] Goeree, J. and L. Yariv (2011). An Experimental Study of Collective Deliberation, Econometrica, 79(3): 893-921.

[35] Green, D. and I. Shapiro (1994), Pathologies of Rational Choice Theory: A Critique of Applications in Political Science, Yale University Press, New Haven.

[36] Grofman, B. (1993), Is Turnout the Paradox that Ate Rational Choice Theory?, in Information, Participation, and Choice: An Economic Theory of Democracy in Perspective, ed. by B. Grofman, chap. 6, Ann Arbor: University of Michigan Press.

[37] Grofman, B., A. Blais, and S. Bowler (2009). Duverger's Law of Plurality Voting: The Logic of Party Competition in Canada, India, the United Kingdom and the United States.

[38] Guarnaschelli, S., R. McKelvey and T. Palfrey (2000), An Experimental Study of Jury Decision Rules, American Political Science Review, 94(2): 407-423. 
[39] Harsanyi, J. (1977), Morality and the Theory of Rational Behavior, Social Research, 44(4): 623-656.

[40] Harsanyi, J. (1992), Game and Decision Theoretic Models in Ethics, in The Handbook of Game Theory, Volume 1, eds. R. Aumann and S. Hart, chap. 19, Amsterdam: Elsevier North-Holland.

[41] Herrera, H. and C. Martinelli (2006), Group Formation and Voter Participation, Theoretical Economics, 1: 461-487.

[42] Jones, M. (2001). Electoral Laws and the Effective Number of Candidates in Presidential Elections, Journal of Politics, 61(1), 171-184.

[43] Kawai, K. and Y. Watanabe (2013). Inferring Strategic Voting, American Economic Review, 103(2): 624-662.

[44] Ledyard, J. (1981), The Paradox of Voting and Candidate Competition: A General Equilibrium Analysis, in Essays in Contemporary Fields o Economics, eds. G. Hoorwich ad J. Quick, Lafayette: Purdue University Press.

[45] Levine, D. and A. Mattozzi (2016). Voter Turnout with Peer Punishment, mimeo, European University Institute.

[46] Li, C. and R. Pique (2016). Ethical Motives for Strategic Voting, mimeo, Princeton University.

[47] Morton, R. (1987), A Group Majority Model of Voting, Social Choice and Welfare, 4(2): $117-31$.

[48] Morton, R. (1991), Groups in Rational Turnout Models, American Journal of Political Science, 35: 758-76.

[49] Morton, R. and T. Rietz (2006). Majority Requirements and Voter Coordination. New York University Annual Survey of American Law, 63(4): 691-726.

[50] Morton, R. and J.-R. Tyran (2012), Ethical vs Selfish Motivations and Turnout in Small and Large Elections, mimeo, New York University. 
[51] Myatt, D. (2007), On the Theory of Strategic Voting, Review of Economic Studies, 74: $255-281$.

[52] Myerson, R. (1998), Population Uncertainty and Poisson Games, International Journal of Game Theory, 27(3): 375-392.

[53] Myerson, R. (2002), Comparison of Scoring Rules in Poisson Voting Games, Journal of Economic Theory, 103: 219-251.

[54] Myerson, R. and R. Weber (1993), A Theory of Voting Equilibria, American Political Science Review, 77: 102--114.

[55] Osborne, M. and A. Slivinski (1996). A Model of Political Competition with CitizenCandidates. Quarterly Journal of Economics, 111: 65-96.

[56] Palfrey, T. and H. Rosenthal (1983), A Strategic Calculus of Voting, Public Choice, 41(1): $7-53$.

[57] Palfrey, T. and H. Rosenthal (1985), Voter Participation and Strategic Uncertainty, American Political Science Review, 79(1): 62-78.

[58] Palfrey, T. (1989), A Mathematical Proof of Duverger's Law, In Models of Strategic Choice in Politics, ed. P. C. Ordeshook, Ann Arbor, Michigan: University of Michigan Press.

[59] Palfrey, T. and D. Levine (2007). The Paradox of Voter Participation? A Laboratory Study, American Political Science Review, 101(1): 143-158.

[60] Piketty, T. (2000), Voting as Communicating, Review of Economic Studies, 67: 169191.

[61] Pons, V. and C. Tricaud (2017). Expressive Voting and Its Cost: Evidence from Runoffs with Two or Three Candidates, Econometrica, forthcoming.

[62] Riker, W. and P. Ordeshook (1968), A Theory of the Calculus of Voting, American Political Science Review, 62: 25-42.

[63] Shachar, R. and B. Nalebuff (1999). Follow the Leader: Theory and Evidence on Political Participation, American Economic Review, 89(3): 525-547. 
[64] Spenkuch, J. (2017). Expressive vs. Pivotal Voters: An Empirical Assessment, mimeo, Northwestern University.

[65] Uhlaner, C. (1989), Rational Turnout: The Neglected Role of Groups, American Journal of Political Science, 33(2): 390-422. 